\title{
Why Do Students Choose English as a Medium of Instruction? A Bourdieusian Perspective on the Study Strategies of Non-Native English Speakers
}

\author{
KLARISSA LUEG \\ RAINER LUEG
}

Aarhus University, Denmark

\begin{abstract}
Taking a Bourdieusian perspective, we analyze the relevance of social background and capital for choosing English as a medium of instruction (EMI). Our work focuses on students with a non-native English-language background in a business school setting. Although proponents argue that EMI generally increases graduates' employability, they do not sufficiently consider that study strategies differ substantially across social milieus and between the sexes. Failing to account for cultural distance of students to the educational system in choosing EMI can foster social inequality and contribute to the reproduction of elites. Using a survey, we conduct a quasi-experiment in two identical bachelor's degree programs that differ only in their instruction language. Using structural equation modeling, we find that students from higher social strata are much more likely to choose EMI. As suggested by the Bourdieusian perspective, this relationship is not directly observable but operates through hidden mechanisms, such as cultural capital (relative English proficiency) and a better sense of gaming and positioning (career orientation). Business students from the lowest stratum self-select against EMI due to a pronounced fear of failure despite their awareness that EMI leads to higher employability. Our findings support the successful introduction of EMI while ensuring social equality.
\end{abstract}

During the last decade, English as a medium of instruction (EMI) has gained attention at universities in non-English-speaking countries (Am-

\footnotetext{
We appreciate the helpful comments on previous versions of this paper from Antoinette Fage-Butler, Morten Jakobsen, Karen Lauridsen, Henning Madsen, Lars Brơd Nielsen, Will Seal, Hanne Tange, the editor Dawn DeTienne, the two anonymous reviewers, and especially Bill Schwartz. Previous versions of this study have been presented at the 19th Conference of the Nordic Network for Intercultural Communication, the 22nd Nordic Academy of Management Conference, and the 3rd Conference of the Actor Reality Perspective (Lueg \& Lueg, 2012, 2013a, b).
}

mon \& McConnell, 2002; Coleman, 2006; Costa \& Coleman, 2012; Maiworm \& Wächter, 2002; Wächter \& Maiworm, 2008). English has become "the language of higher education" in Europe (Coleman, 2004), and non-Anglo-American countries (Byun, Chu, Kim, Pork, Kim, \& Jung, 2011). By introducing EMI into the curriculum, institutions in higher education (HE) attempt to improve the internationalization of management education (Doh, 2010). Governments argue in favor of this development due to "the near-necessity of English proficiency for graduate employability" 
(Costa \& Coleman, 2012: 2), and at business schools, students consider EMI as an antecedent to career opportunities (Byun et al., 2011).

Such instrumental approaches to elite education often have been addressed by critical management education (CME). Vaara and Faÿ (2011) argue that the choice to obtain an MBA reflects the desire for status and access to a network rather than the desire for knowledge. Such strategies are often successful; organizations favor elite graduates in hiring (Rivera, 2011) and promotion (Forbes \& Piercy, 1991; Ishida \& Spilerman, 2002; Kim \& Cannella, 2008). Also, superiors attribute more weight to degrees than to professional achievements when evaluating an employee with on elite education (Festing \& Barzantny, 2008). Even within the highest echelon of management, elite education is associated with stratification: Useem and Karabel (1986) demonstrate that the odds of being a CEO in the United States were much higher for senior managers with bachelor's degrees from elite universities and upper-class backgrounds (see also Ott, 2011). As another example, McDonald and Westphal (2011) show that CEOs who perceive themselves among the CEO elite are much more supportive of their elite peers (see also Westphal \& Khanna, 2003). According to upper echelon theory (Finkelstein \& Hambrick, 1996), these individual's choices can exert substantial effects on organizational outcomes or even economic structures. As an example, Burkert and Lueg (2013) show that top managers' preferences for shareholderoriented governance relate to their educational backgrounds. The authors argue that such preferences are not just an outcome of business school educations but reflect the managers' selfselection into certain educational programs.

We are specifically interested in the EMI-related implications for elite management education. Recent research on the transformation of cultural capital and the reproduction of class patterns shows that an international orientation contrasts with the "provincial" orientation (Prieur \& Savage, 2011: 576). Yet, the link from social background to language choice has not been discussed in this respect. Higher education (HE) institutions are crucial settings for social positioning, where the students' strategies influence success and failure. Because selection processes in HE often occur to the disadvantage of the culturally underprivileged, we specifically investigate the social backgrounds of students who decide for or against EMI. Failure to account for different social backgrounds and diver- sity among students can foster social inequality and the reproduction of elites (Finkelstein \& Hambrick, 1996: 104; Vaara \& Faÿ, 2012). To address this gap-while accounting for alternative explanations of language choice-we pose the rather broad research question: "Why do non-native English language speaking students choose EMI in a non-English-speaking setting?" Thereby, we respond to calls for research on the internationalization of management education and its effects on the reproduction of elites (Doh, 2010; Vaara \& Faÿ, 2012).

We approach this question using a quasiexperiment at Aorhus University (AU), Denmark, for which we employ a questionnaire that we evaluate with partial least squares (PLS). Aarhus University's bachelor of science in economics and business administration program offers students two identical options that differ only in their medium of instruction (English or Danish). Our findings suggest that students see EMI as a means of distinction. Hence, high social background indirectly fosters the choice of EMI through habitus and cultural capital. The fear of academic failure of lower-strata students decreases their probability of choosing EMI. Moreover, the reasons for choosing EMI differ across social strata. Students from higher strata make a less peer-dependent and a more cultural-capital related choice for EMI. In addition, the EMI choice of students from the lowest stratum is not driven by personal motives of employability, but by peer pressure (females) and peer and family pressure (males).

These findings have several implications. Although EMI is important for the future of higher education, its "unmindful" implementation may induce an unbalanced allocation of additional cultural capital among students. Policy makers can counteract these dysfunctional effects by accounting for gendered study strategies, and by demonstrating to the individual student that EMI does not pose insurmountable barriers to successful learning but offers opportunities. Simply stressing the general career relevance of the English language or raising absolute English proficiency among students, however, are not sufficient to convince lower-strata students to choose EMI.

In the following section, we introduce theoretical concepts by Pierre Bourdieu as the basis for our hypotheses development. We then explain our research design, and present its results, followed by a discussion of implications, limitations, future research, and a conclusion. 


\section{THEORETICAL BACKGROUND}

\section{Boon and Bane of English in International Management Education}

Both the rapid diffusion of EMI and internationalized education are controversial (Harder, 2009; Jeong, 2004; Kang, 2012; Park, 2009; Seth, 2002). For instance, politicians have proposed to protect local languages and culture against English as a European lingua franca (e.g., in Denmark: Kulturministeriet, 2003). Related research-specifically from $\mathrm{CME}-$ has investigated various aspects of internationalized management education (Doh, 2010), such as the diffusion of Anglo-American concepts and values (Engwall, 2004; Krishnan, 2008; Sturdy \& Gabriel, 2000); the global institutionalization of management education (Goodrick, 2002; Spender, 2005; Zald, 2002); or the reproduction of elites through specialized programs and institutions (Useem \& Karabel, 1986; Vaara \& Faÿ, 2012). Harder (2009: 8) identifies two central themes in the EMI debate: the possibility of "domain loss" of the domestic language and danger of segregation between an English-oriented elite and a locally oriented majority. This latter "man in the street" is often represented by right-wing political parties, which attempt to ban the English language from national universities (e.g., Folkeparti, 2009). But this resistance against Anglo-American influences has not stopped the general political tendency to support further internationalization, as evidenced, for example, by the steadily advancing Bologna Process in Europe (Powell \& Solga, 2010).

\section{Bourdieusian Theory and Language}

In this article, we aim to understand the choice of EMI in management education from a Bourdieusian perspective. Bourdieu proposes that the academic success or failure of children from different social strata is not just a result of effort or natural aptitude, but is mainly dependent on their cultural distance from the educational institutions (Bourdieu, 1997: 47; Bourdieu \& Passeron, 1977; Bourdieu, Passeron, \& Saint Martin, 1994a: 35-36).

The three key concepts within Bourdieu's theory of social reproduction are social class, capital, and habitus. Class constitutes the primary determinant of an agent's social and professional development (Bourdieu \& Passeron, 1977: 89). Agents from different classes have varying relationships to practices in $\mathrm{HE}$, and the offspring of the dominant, higher classes are favorably positioned to meet the re- quirements of the educational system (Bourdieu \& Passeron, 1977: 200).

This interplay of the educational system and the abilities of agents to perform within that system is predicated on Bourdieu's (1997: 46) general definition of capital. An agent's capital

[I]s a force inscribed in the objectivity of things so that everything is not equally possible or impossible. And the structure of the distribution of the different types and subtypes of capital at a given moment in time represents the immanent structure of the social world [...], determining the chances of success for practices.

Bourdieu (1997) distinguishes among four types of capital: Economic capital comprises physical assets that can be converted into cash; social capital includes the possession of a durable network or a social group membership; and-most important with regard to higher education and language-cultural capital. Cultural capital is classified into three types: The embodied form is unconsciously bequeathed within the formily and covers competences and knowledge. It is "the best hidden and socially most determinant educational investment" (Bourdieu, 1997: 48) because it is "recognized as legitimate competence" (Bourdieu, 1977b: 49). Bourdieu and Passeron (1977: 74) specifically use the term "linguistic capital" as a complement of embodied cultural capital. Because an academic language is "unequally distant from the language actually spoken by the different social classes" (Bourdieu \& Passeron, 1994: 8), academic success is determined by linguistic inheritance (Bourdieu \& Passeron, 1977: 73; Bourdieu, Passeron, \& Saint Martin, 1994b: 37). Cultural capital furthermore exists in the objectified form, that is, in books or instruments and in the institutionalized form, that is, as credentials from authorized institutions (Bourdieu, 1997: 47). A fourth type of capital is symbolic capital. Symbolic capital consists of other types of capital that are recognized as legitimate. It grants its agent credibility and distinction (Bourdieu, 2005: 195).

The product of social class and the provision of capital types is the habitus, a complex system of "perceptions, appreciations, and actions" based on experiences (Bourdieu, 1971: 83). Habitus is a "sense of limits" as well as a "sense of one's place" (Bourdieu, 1984: 471) that determines whether on agent feels comfortable with the rules and sym- 
bolic values of a field. An unsuitable habitus may lead to socially disadvantageous decisions such as self-exclusion from an educational field; therefore, there is a strong relationship among the unequal possession of cultural capital, habitus, and education and career choices.

We conjecture that family background has on indirect effect on the choice of EMI. At the same time, we postulate that EMI functions as distinguishing symbolic capital (Bourdieu, 1991: 55) in contemporary Denmark. We do so because the government and the examined university accredit EMI as a legitimate form of cultural capital in the global labor market. ${ }^{1}$ Thereby, cultural and symbolic capital "become the condition for legitimate access to a growing number of positions" (Bourdieu, 1977b: 55). Therefore, the certified capability to master the "legitimate language" (Bourdieu, 1991: 45) of the field facilitates accumulation of capital and social positioning.

There are several examples of the value of the English language in management (Maclean, Harvey, \& Chia, 2012; Ott, 2011). Engwall (2004) documents how, since the 1950s, the AngloAmericanization of Scandinavian business schools has not just led to a change in language but also to a general shift from a German tradition toward an American focus on finance and microeconomics (Engwall, 2004). This transformation has created an Anglo-American "management grammar" that elite graduates use (Vaara \& Faÿ, 2011: 7; Weißenberger \& Angelkort, 2011).

As Prieur and Savage (2011: 575) note, one difference between the culturally privileged and nonprivileged in Denmark is a difference in "international vs local or national orientation." Thus, we find it reasonable to assume that an EMI education functions as an important signifier for such a stratifying international orientation. Language-especially in its institutionalized and symbolic capital forms-becomes a vehicle for the creation of social and economic capital. Therefore, a social strata division between those who opt for and those who refrain from EMI may be considered a step toward the reproduction of uneven sociocultural privileges.

\footnotetext{
${ }^{1}$ We acknowledge that other ascriptions of symbolic capital are possible, especially within studies that are more oriented toward a national job market and a national research tradition, e.g., history or law.
}

\section{Connection to Alternative Theories}

Alternatives to Bourdieusian theory to explain decision making include the concept of self-efficacy (Schwarzer \& Jerusalem, 1995), and the theory of planned behavior (TPB; see Ajzen, 1985; Ajzen \& Madden, 1986). Because both approaches focus on agency, they exhibit some axiomatic conflicts with the Bourdieusian approach (Bourdieu, 2003b, 2005: 215-216, 220).

\section{Self-Efficacy and the Theory of Planned Behavior}

Perceived self-efficacy is a concept within Bandura's $(1993,2001)$ social cognitive theory, meaning the belief in one's ability to produce a desired effect (Scholz, Doña, Sud, \& Schwarzer, 2002: 242). Agents tend to seek environments where success is likely (Bandura, 1993: 135). This results in committing to more challenging tasks (Scholz et al., 2002: 242) and-given the relevant skills-higher achievements. This will determine positioning in a certain environment and henceforward agents' behavior will be-consistent with the Bourdieusian interpretation-"partly the product of their environment" (Bandura, 1993: 135). Going beyond specific situations, Schwarzer and Jerusalem (1995) introduced a scale for measuring general selfefficacy (GSE), a "global confidence in one's coping ability" (Luszczynska, Gutiérez-Doña, \& Schwarzer, 2005: 81).

The theory of planned behavior (TPB) claims that agents use their experience to estimate their perceived behavioral control (PBC), that is, how challenging a certain behavior is to them (Ajzen, 1991: 196). Additional elements of TPB are behavioral beliefs that estimate how effective the behavior will be and influence attitudes toward the behavior. Normative beliefs are assumptions about how important others consider the behavior and form subjective norms on the basis of perceived social pressure (Ajzen \& Fishbein, 2005: 194). Given the similarity of PBC and self-efficacy, Kraft, Rise, Sutton, and Røysamb (2005: 493) suggest reconceptualizing $\mathrm{PBC}$ as "two separate but interrelated constructs, namely self-efficacy and controllability."

\section{Differentiating the Bourdieusian Approach From $T P B$ and Self-Efficacy}

Three characteristics distinguish the Bourdieusian approach from TPB and self-efficacy: (1) the role of social structures, (2) the role of power structures 
and cultural meanings, and (3) the process of decision making.

For social structures Bourdieu's (1989: 14) agency-integrating "constructivist structuralism" centers on the class-specific habitus. The concept of habitus was initially constructed to integrate subjectivism and objectivism (Bourdieu, 1990a: 10). There are some parallel elements of normative beliefs and subjective norms (see Schultz, Nolan, Cialdini, Goldstein, \& Griskevicius, 2007) and social capital, but these differ in their reflection of agency and structure. From a Bourdieusian perspective, beliefs and norms correspond, are "doxical" (Bourdieu, 1998: 81) with the environment. Agents assemble in "elective affinities" (Bourdieu, 1984: 238). Thus, the Bourdieusion perspective assumes concordance between social capital and habitus.

The Bourdieusian perspective elaborates the concepts of power and the cultural meaning of behavior more fully than TPB or self-efficacy. Selfefficacy does not explain how it emerges and differs in social contexts (Burke et al., 2009b). On the contrary, the Bourdieusian perspective sees "cultural accessibility and capital" (a power dimension) as an antecedent of self-efficacy (Bandura, 1993: 142).

In addition, the consciousness and controllability aspects of decision making are conceptualized differently. In the Bourdieusian conception, a rather unconscious "feel for the game" (Bourdieu, 1990a: 9) will lead to success, while the culturally distanced might be led by misbelief (Bourdieu, 1984: 321). Agents can still make decisions in Bourdieusian theory. But, eventually, any self-efficacy will be predirected to habitus-corresponding fields (doxa). Recent research tries to align selfefficacy and social context (Boardman \& Robert, 2000; Burke et al., 2009b; Kiilo \& Kutsar, 2012), expressing the hope that

if it can be demonstrated that self-efficacy is dependent, to some degree, on the location of an individual in the broader macrosocial order, then self-efficacy may provide a conceptual bridge between structure and agency (Boordman \& Robert, 2000, 119).

In summary, Bourdieu (1977b, 1990a) addresses this integration problem effectively on a theoretical level with the concept of habitus. Yet, a main challenge for its empirical applicability is the lack of constructs at the agent level. Thus, integrating self-efficacy into the application of Bourdieusian theory (e.g., feel for the game, doxa, etc.) will be productive when agents are confronted with an either-or choice (Boardman \& Robert, 2000: 119).

\section{HYPOTHESES DEVELOPMENT: SOCIAL STRATA AND EMI}

We derive hypotheses relating to social background, cultural capital, and habitus. We specifically investigate the expected need for and the expected advantage of English proficiency on the labor market, absolute English proficiency, and the borriers to choosing EMI (see Figure 1).

Bourdieu (1984: 471) suggests that the offspring of the established strata have a "sense of one's place," which allows them to identify distinct positions in society and to equip themselves with the required qualifications. Competing agents from lower strata have less valuable predispositions that limit the scope of their actions to achieve such positions. Their exclusion is mainly accomplished through the higher-strata agents' shared habitus and common agreement on the underlying structures, principles, and boundaries of the field (doxa).

The codes and meanings of the fields of interest-in this case both the field of education and the economic field-are primarily cognizable for agents with matching predispositions, that is, cultural capital (Bourdieu, 1998). Therefore, we expect mediating effects between background and EMI through habitus, cultural capital, and habitus-field correspondence. Still, a possible direct relationship between social origin and EMI has to be tested. Therefore, we propose:

Hypothesis la: The higher the social background, the more likely the choice of EMI.

In addition to its symbolic value, there is strong evidence that English proficiency has become a necessity for conducting transnational business in Europe (Vaara, Tienari, Piekkari, \& Söntti, 2005). Business transactions in the EU are carried out primarily in English (Ginsburgh \& Weber, 2011), and managers are expected to be proficient (Louhiala-Salminen, Charles, \& Kankaanranta, 2005). In Denmark, due to its relatively small domestic market, even small companies are highly internationalized (Firth, 1996; Knight, Madsen, \& Servais, 2004; Moen \& Servais, 2002; Pedersen, 2000; Servais \& Jensen, 2001). We assert that the strata-dependent abilities of students to recognize these structural requirements and trends in the economic field lead to 


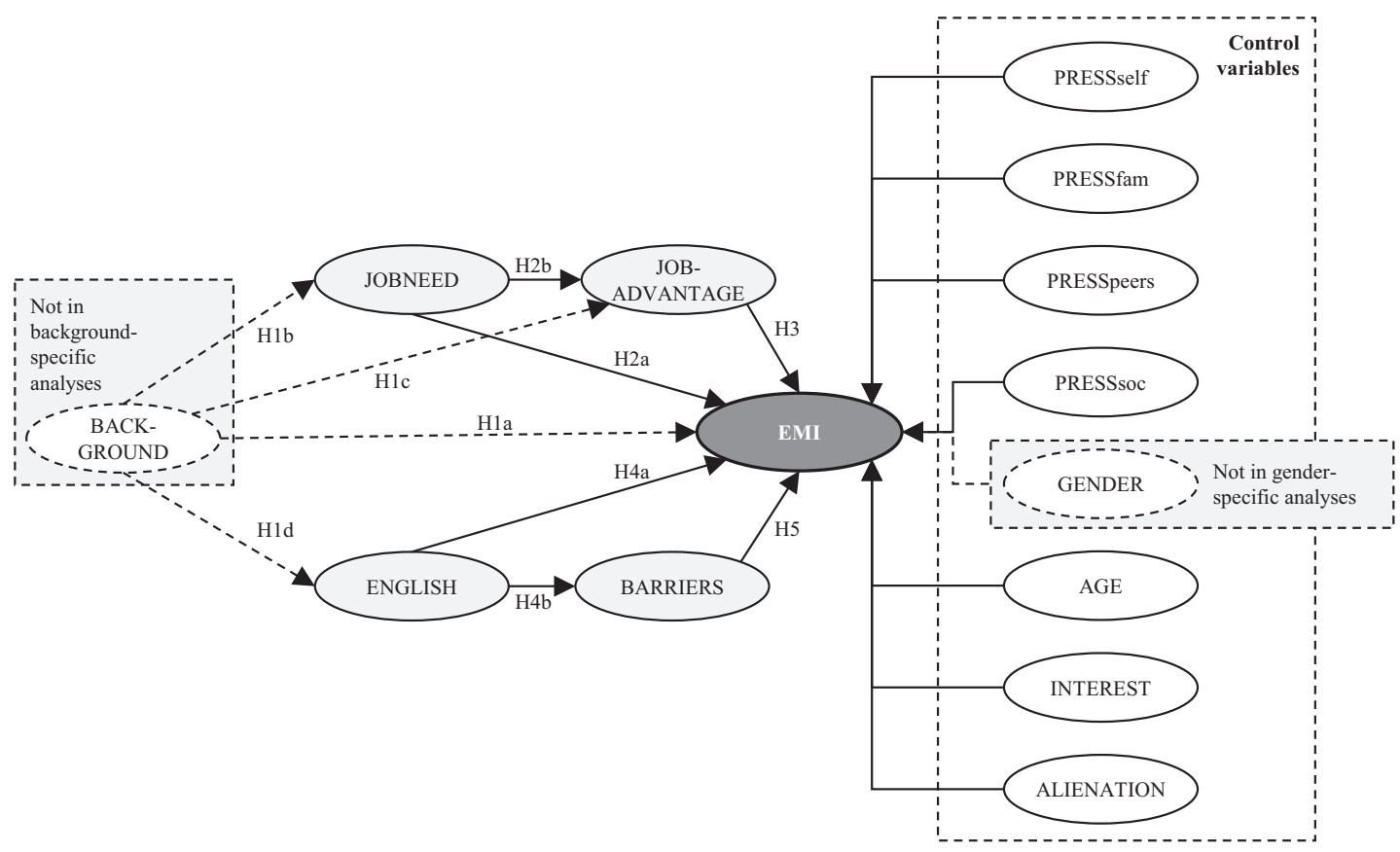

FIGURE 1

Theoretical Model

diverging response strategies (Bourdieu, 1996; Bourdieu \& Passeron, 1977: 184). To expect that students from higher strata are more likely to, first, detect the importance of English proficiency in the job market, and second, to realize that choosing EMI and acquiring the institutionalized cultural capital of English proficiency is an advantageous strategy for their individual employment is plausible. Thus, we propose Hypotheses lb, lc:

Hypothesis 1b: The higher the social background, the higher the expectation of English as the working language.

Hypothesis lc: The higher the social background, the greater the expected employment advantage from EMI.

A large number of studies have investigated the determinants of successful foreign language learning) from elementary school through higher education. Consistent predictors of success in a foreign language are high social background and the sophisticated use of one's mother tongue (for an extended literature review, see Pishghadam, Noghani, \& Zabihi, 2011). Conversely, the feeling of impotence negatively affects lower-strata students' success in a second language (Schumann, 1978). This suggests a positive relationship between foreign language learning and social as well as cultural capital (Bourdieu et al., 1994a;
Bourdieu, 1977a, 1991; Clemente, 2007; Hinkel, 2005; Pennycook, 2001; Pishghadam, Noghani, \& Zabihi, 2011). In addition, inherited upper-class rhetoric is rewarded because it resembles the rhetoric prevalent in academic institutions (Baudelot, 1994; Bourdieu, 1977a). Last, these factors lead to higher levels of self-confidence and goal attainment for higher-strata students (Bourdieu, 1977a, 1984). We therefore propose Hypothesis Hld:

Hypothesis ld: The higher the social background, the higher the perceived English proficiency.

One of the main institutional arguments for adopting EMI refers to increased job opportunities for graduates. Still, the empirical evidence on the link between the students' expectations of an internationalized labor market and their study behavior-the choice of EMI-is scarce (Tung, Lam, \& Tsang, 1997). Such reasonable mechanisms have been addressed by TPB's precursor, the theory of reasoned action, as well as informationmotivation-behavioral skills models (Ajzen \& Fishbein, 2005; Fisher \& Fisher, 1992). On the one hand, beliefs about the importance of an issue affect behavior (Ajzen \& Fishbein, 2005). This corresponds to the conjecture that English will be important in a professional setting. It also supports the view that understanding job market requirements, de- 
tecting the advantages of a certain behavior, and acting accordingly are synonymous. On the other hand, the TPB model suggests that having an attitude toward a general issue and acting upon it are two different things (Ajzen, 1991). TPB emphasizes that self-efficacy (parallel to attitudes and norms) directly impacts behavior. Self-efficacy can be seen as an indicator of habitual mechanisms. Bourdieusian theory objects to the assumption that there is a continuity from the realization of the general importance of EMI to its specific importance for one's employability, and then for the choice for EMI. Even if all agents are aware of the demand for and the advantages of EMI, not all will act upon it. This is due to sociocultural barriers, such as the hysteresis effect, that is, "the foundation of the structural lag between opportunities and the dispositions to grasp them" (Bourdieu, 1977b: 83). These two links cannot be assumed but must be tested. We propose two hypotheses:

Hypothesis 2a: The expectation of English as working language positively impacts the choice of EMI.

Hypothesis 2b: The expectation of English as working language positively imparts the expected employment advantages.

Evidence from Europe (Adshead \& Jamieson, 2008; Felix, 2006; Lauer, 2002) and the United States (Wilson, Wolfe, \& Haveman, 2005) suggests that career-related considerations outweigh personal motives, for example, the student's genuine interest in a subject. With respect to EMI, several nonEuropean studies document that job advantages are a main reason for choosing EMI (Byun et al., 2011; Diab, 2006; Tung et al., 1997; Yang \& Lau, 2003). However, evidence from Europe is scant (for the exception, see Gardner, 1985). Especially in Denmark, employers communicate that English is needed at workplaces (Going Global, 2006; Sørensen, 2005; Tange, 2008; Tange \& Lauring, 2009).

We assert that students who consider English to be advantageous for their future employment will be more likely to signal their English proficiency. It is probable that they attempt to acquire more valuable institutionalized cultural capital, which can take the form of a degree from an EMI program. Hence, we propose:

Hypothesis 3: The greater the expected employment advantages of English, the more likely the choice of EMI.
English proficiency is a source of self-esteem for students and young graduates (Andrade, 2009; Ball \& Chik, 2001; Tsai,Ying \& Lee, 2001). An agent's self-esteem is rooted in possessing the characteristics that a society considers desirable, meaning cultural capital in its legitimized form (Bourdieu, 2005). As Prieur and Savage (2011: 567) demonstrate, an "international orientation" is associated with cultural privileges, with a higher level of education and with common recognition.

English proficiency can function as symbolic capital and as a sign of distinction within the frame of international orientation. Students who already rate their English proficiency highly will employ a relatively risk-free but high-yielding strategy of "succession" (Bourdieu, 1975: 30). They try to convert their embodied form of cultural capital (English proficiency) into a legitimized form (a degree with EMI). So, they transfer their relatively high cultural and symbolic capital in the field of education into the economic field. We therefore propose:

Hypothesis 4a: The higher the level of English proficiency, the more likely the choice of EMI.

Despite all the potential benefits, there are some barriers to choosing EMI (Hu, 2009; Hu \& Alsagoff, 2010; Kang, 2012; Park, 2009). Some authors argue that it is easier to learn in one's mother tongue than to learn in English (Christensen, 2009; Gottlieb, 2009). This implies that students' comprehension, participation, and exam performance could be negatively affected by EMI. Students are intrinsically motivated to strive for embodied cultural capital (H4a, English proficiency). Yet, students are also extrinsically motivated to strive for rewarding institutionalized cultural capital, manifested in high grades and their final diplomas (Bourdieu, 1979b; Elliot \& Knight, 2005; Sullivan, 2009a; Sullivan, 2009b; Vallerand, Pelletier, Blais, Briere, Senecal, \& Vallieres, 1992). Therefore, students from all strata may worry about receiving lower grades due to EMI (Abedi \& Lord, 2001; Christensen, 2009).

Yet, EMI signals distinction and a strong position in the educational and economic fields. Therefore, students will try to overcome barriers to EMI. The gap in understanding between content taught in English and Danish should narrow (relative English proficiency increases) as the absolute English proficiency increases. Hence, we propose: 
Hypothesis 4b: The higher the level of English proficiency, the lower the barriers to choosing EMI.

Absolute English proficiency is just a part of relative English proficiency because students' initial assessments of their personal gaps matter. A number of studies show that insecurity and perceived obstacles lead to higher drop-out rates or ex-ante avoidance of programs that are associated with obstacles (Araque, Roldón, \& Salguero, 2009; Belloc, Maruotti, \& Petrella, 2010; Bennett, 2003; Lassibille \& Navarro Gómez, 2008). From a Bourdieusian perspective, this behavior reveals a strategy. Swartz (1997: 100) argues that each agent intends to use her time in a profit-oriented manner, with actions deriving "from sets of dispositions that internalize in practical form what seems appropriate or possible in situations of challenge." For EMI, this implies that the expectation of barriers (low English proficiency, inferior performance) leads to strategies of "self-elimination" or "selfexclusion" (Bourdieu \& Passeron, 1977: 42, 154). Students who do not choose EMI protect themselves from being eliminated by the academic selection process (exams) after they have already invested their time (Bourdieu \& Passeron, 1977: 153). By choosing the Danish medium of instruction (DMI), they also protect themselves against a negative impact on their institutionalized cultural capital, that is, against lower grades (Christensen, 2009: 58). We propose:

Hypothesis 5: The higher the expectation of barriers (inferior use of time, lower grades), the less likely the choice of EMI.

\section{RESEARCH DESIGN}

\section{Sample Selection}

The target population is first-semester students enrolled in the bachelor of science in economics and business administration program at $A U$ during the fall 2011 term. This program was mainly taught in Danish until 1997, when on identical program with EMI was introduced. The total number of enrolled Danish and international students increased by 272\% from 345 in 1997 (45 chose EMI, i.e., 13\%) to 937 in 2011 (174 choose EMI, i.e., 19\%). During the last 5 years (2007-2011), 13-23\% of all students enrolled in this bachelor program chose EMI. The enrollment differences in DMI and EMI fluctuated randomly. We conducted our quasi-experiment employing a survey in the beginning of a mandatory course (Financial Accounting I) to increase participation.

The context of AU in Denmark presents an excellent opportunity to discover the reasons for the EMI choice. First, most enrolled students are Danes. Because Danes possess high levels of English proficiency, they can easily choose either program. Eighty-six percent of all Danes consider themselves fluent enough to have a conversation in English (European Commission, 2006). Educational Testing Service (2011) shows that Danish test takers rank second among 165 countries in the Test of English as a Foreign Language with an average of 99 out of 120 points. Given this bilingualism and the increasing presence of EMI in educational contexts, self-selection against EMI suggests hidden social reasons.

Second, approximately $25 \%$ of all Danish university programs were offered in English as of 2007 (198 of 810). As of today, the Danish Ministry of Science, Innovation and Higher Education (2012) lists 145 master's programs and 60 bachelor's programs offered in English at Danish universities. Aorhus University offers 65 complete degree programs in English (Aarhus University, 2012).

Third, Denmark is less socially stratified in the field of education than most other countries (United Nations Development Programme, 2011). Therefore, our findings should have validity for more stratified societies (for a recent update on stratification in Europe, see Oesch, 2006) where students are more likely to be selected socially and have higher aversion to choosing EMI (Orr, Gwos, \& Netz, 2011).

\section{Data Collection}

We collected the data using a questionnaire in September 2011. In total, 937 students were registered for the relevant BSc programs. All studentsirrespective of their chosen instruction languagehad to document outstanding English proficiency upon their registration, corresponding to a grade of $\mathrm{B}$ in secondary school English. ${ }^{2}$ The students were taught in five sections, four with DMI and one with EMI. Total attendance in the five sections was 706 students (=100\%). We briefly presented the study and distributed a questionnaire during the first $15 \mathrm{~min}$ of the course. Of the students present for the

\footnotetext{
${ }^{2}$ This corresponds to 83 TOEFL points, 6.5 IELTS points, the Certificate in Advanced English (CAE), or a Cl-level according to CEFR. All other requirements are equal.
} 
study, 30 (4.2\%) failed to complete substantial parts of the questionnaire and were eliminated from the sample. Of the remaining 676 students, we eliminated 60 non-Danish students because they could not choose DMI in the first place. Our final sample consisted of 616 Danish students who had chosen either DMI or EMI (an $87.3 \%$ response rate). The mean student age was 21.0 years $(S D=2.034)$ and $15.4 \%$ had chosen EMI $(S D=0.361)$. In the sample, $61.2 \%$ of the students were female ( $\mathrm{S} D=0.488$ ). The data from the original 676 paper questionnaires were digitized by a professional analytics group. ${ }^{3}$

\section{Measurement}

We created constructs for EMI choice and developed the corresponding questionnaire according to contemporary standards (Bedeian, 2007; Bisbe, Batista-Foguet, \& Chenhall, 2007). We started with a literature review to draft preliminary constructs. We then used three groups of pretesters. The first group was comprised of program administrators of the BSc and MSc programs at AU (Aarhus University). The second group was composed of thirdsemester BSc students, and the third group consisted of lecturers from the BSc program. In the first meeting, the pretesters commented on the overall questionnaire. These comments helped us to refine the preliminary constructs and to eliminate indicators. In subsequent meetings, the pretesters filled out the questionnaires and provided additional feedback. For the classes using DMI, certified experts translated the questionnaires into Danish using the translation-back-translation method (Brislin, Lonner, \& Thorndike, 1973).

Except for EMI, AGE and SEX, we measure all items using a Likert scale ranging from 1 ("does not apply at all") to 7 ("fully applies"). We created 10 constructs that represent possible reasons for choosing EMI:

JOBNEED measures whether the student expects English to be part of a daily working routine.

JOBADVANTAGE measures the association between possessing English skills and subsequent job opportunities, qualification levels, and salaries

\footnotetext{
${ }^{3}$ An independent coder reviewed 34 (5.03\%) questionnaires to corroborate that the original data was correctly transformed. The error rate of data points was a negligible $0.37 \%$, and we adjusted the identified items. The errors were mostly related to marking the adjacent option on scale, e.g., digitizing ' 2 ' or ' 4 ' when the respondent marked ' 3 .'
}

(for both, also see Clachar, 1997; Kakh, Mansor, \& Zakaria, 2012; Yang \& Lau, 2003).

ENGLISH is a self-assessment of proficiency in reading, writing, and speaking English. We refrained from using an archival measure such as a high school grade because we argue that the choice of EMI depends on the student's perceived proficiency rather than the objective assessments of third parties (also see, Muda et al., 2012; Yeung, Lau, \& Nie, 2011).

BARRIERS captures the fear of missing out on course content, on course discussions, or on a higher grade in an EMI program due to relatively lower English skills.

To avoid omitted variable bias and endogeneity, we control for alternative explanatory variables in the choice of EMI. In addition to SEX and AGE, we assess the study participants' general interest in foreign cultures and languages (INTEREST). This measure represents an intrinsic motivation to choose EMI (also see, Holme \& Chalauisaeng, 2006; Rafee, Mustafa, Shahabudin, Razali, \& Hassan, 2012; Yeung et al., 2011).

ALIENATION assesses the attitude of the student toward the diffusion of English in Denmark. To prevent social desirability bias, we employ an indirect measurement, for example, "Some people think that the following statements are correct. Do you agree with them?" (also see, Clachar, 1997).

We employ several constructs that suggest pressure on students to choose EMI. PRESSself is the most immediate and captures the professional ambition of the student (Lee, McInerney, Liem, \& Ortiga, 2010; Maltby et al., 2008). PRESSfam measures the family's attitude toward educational achievement (also see, Jacobs \& Harvey, 2005). PRESSpeers indicates the influence of the student's peers on the choice of EMI (Nelson \& DeBacker, 2008). PRESSsoc indirectly measures pressure from society by assessing the student's view on English as symbolic capital in Danish society (also see, Clachar, 1997; Yang \& Lau, 2003).

Exploratory factor analyses provide evidence that the individual items on the survey load onto the 10 underlying constructs as expected. We extracted 10 factors and reran the analyses after eliminating all items with a factor loading of less than 0.4. Only 2 of 46 items were dropped using this criterion. We used variable imputation to resolve the few cases of item nonresponse. Table 1 lists all the questionnaire items in full, as well as their descriptive statistics.

The factor analyses provide evidence that we correctly identify all multi-item constructs; they 


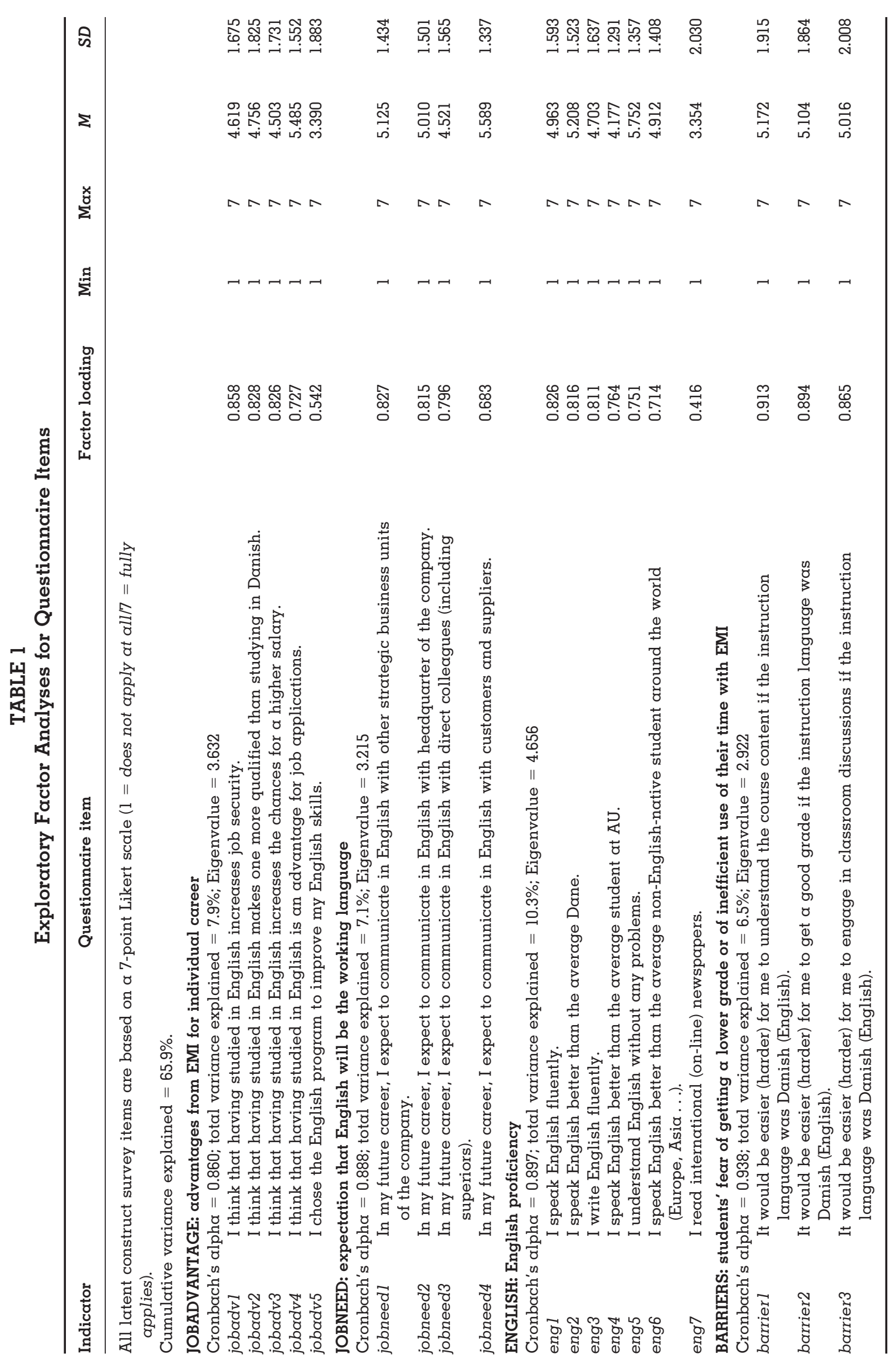




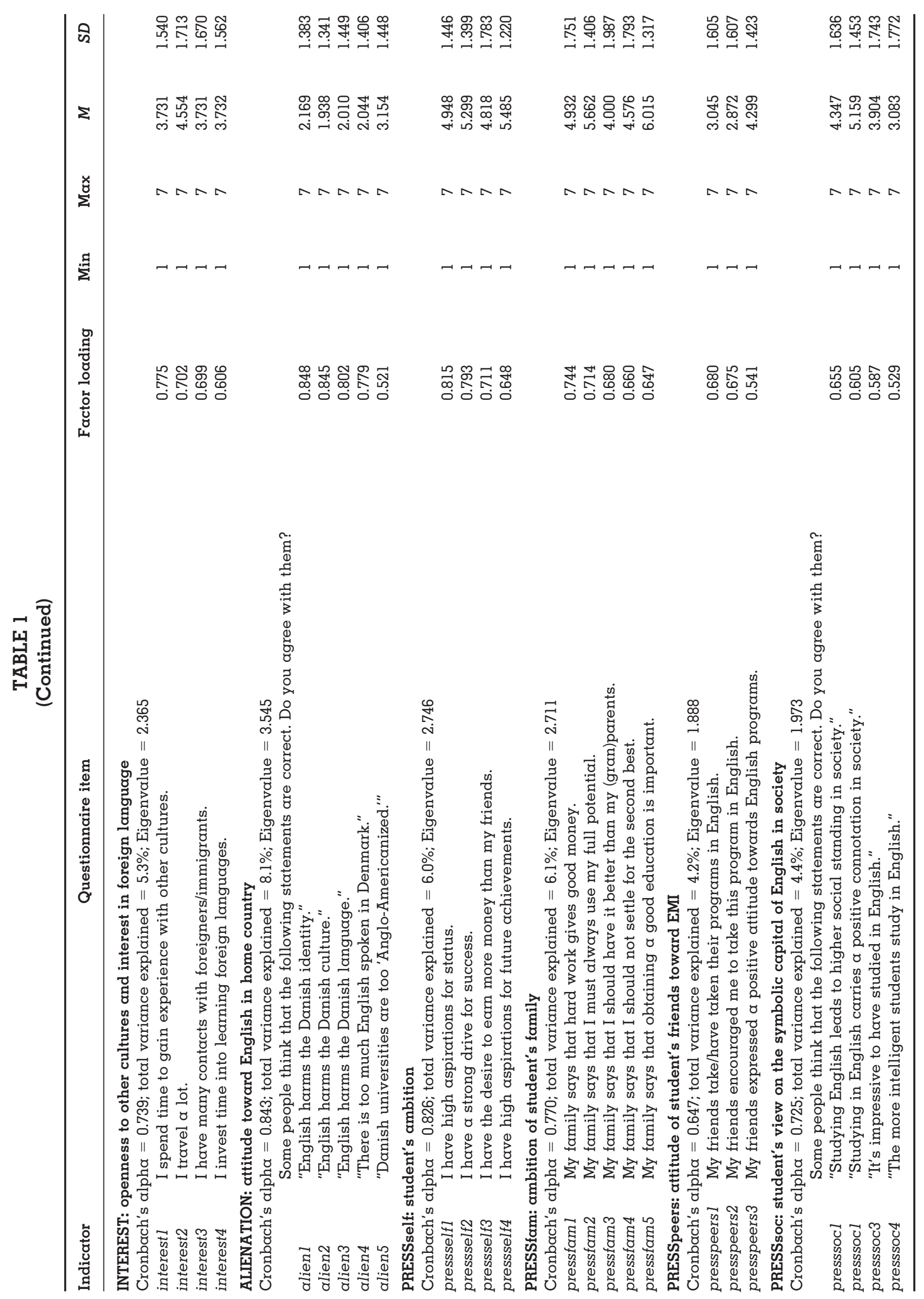


have Cronbach's (1951) alphas ranging from 0.647 to 0.938. All but one Cronbach's alpha pass the traditionally required threshold of 0.7 (Nunnally, 1978). Following Hair, Black, Babin, and Anderson (2009) on the development of new scales, we also kept the construct PRESSpeers despite its Cronbach's (1951) alpha of 0.647. We later test the reliability and validity of these scales in the PLS measurement model. Together, the 10 constructs explain $65.9 \%$ of the variance in the data.

We assess the social BACKGROUND of a student based on the parents' social standing, that is, a combination of the parents' academic degrees and their subsequent professional careers (Isserstedt, Middendorf, Kandulla, Borchert, \& Leszczensky, 2010; Orr et al., 2011). These social background scales have been developed and adjusted for several European countries, including Denmark. Table 2 summarizes the construct and the data.

The highest combination (either the father or the mother) determines the student's social background. Following Isserstedt and colleagues (2010), we group the students into four social strata, including lower middle (1), middle (2), upper middle (3) and high (4). Compared to previous work by Orr and colleagues (2011: 244), our sample of students in management is representative of the Danish student population in terms of sex and social background, which consists of $59 \%$ female students (vs. our $61.2 \%$ ) and students with social backgrounds classified as "low qualification" (8\% vs. our $8.8 \%$ "lower middle"), "nontertiary education" (13\% vs. our 18.0\% "middle"), and "high qualification" (79\% vs. our 73.2 "upper middle"/"high"). We find that in $48.9 \%$ of cases, at least one parent has an academic degree. In $18.2 \%$ of cases, both parents have an academic background. Table 3 indicates that there is no sex-specific difference in the social backgrounds of the students $\left(\chi^{2}=3.940 ; p>.1\right)$.

For the variable EMI, we asked students if they had chosen the program with DMI ("0") or EMI ("l"). We corroborated the results from the questionnaire with our observations; all students attending the EMI class chose "1." Ten students in the other four DMI sections also chose "l," supposedly because the time of the day was more convenient for them.

We measure the variable AGE in full years. SEX is measured as a binary variable $(0=$ male; $1=$ female). Table 4 lists the means, standard deviations and pairwise correlations among all variables. The square root of the average variance extracted (AVE) for each construct is listed in bold on the diagonal. The relatively high values com- pared to the correlation coefficients indicate sufficient discriminant validity of our identified constructs (Chin, 1998; Fornell \& Larcker, 1981).

\section{RESULTS}

To analyze our data, we use PLS because it is applicable to the more detailed analyses of smaller subsamples of our data (Wold, 1985). PLS simultaneously assesses a measurement model and a structural model (Barclay, Thompson, \& Higgins, 1995). In the first step, we evaluate the measurement model, which assesses the validity and reliability of our constructs by specifying their relations to the indicators from the questionnaire. In the second step, we interpret the structural model, which reveals the relationships among the constructs (hypotheses tests).

\section{Measurement Model}

All but two questionnaire items load above the 0.5 level on the relevant constructs. ${ }^{4}$ The loading of each questionnaire item on its assigned construct exceeds the loadings on any other construct (Chin, 1998). Table 5 lists the Cronbach's (1951) alphas, composite reliability (CR), and AVE for each construct. Using Fornell and Larcker's (1981) measure of CR, all constructs-including PRESSpeers-are above the required level of 0.7 (Nunnally, 1978). The AVE measures are above or near 0.5 (0.49 for PRESSfam), which supports the convergent validity of the constructs (Chin, 1998; Hair et al., 2009).

We also assess whether each construct shares more variance with its indicators than with the other identified constructs, that is, its discriminant validity (Fornell \& Larcker, 1981). On the diagonal, Table 4 demonstrates that the square roots of the AVE clearly exceed the relevant binary correlations with all other constructs (Chin, 1998). Thus, the reliability and validity are satisfactory for all constructs.

\section{Structural Model and Hypotheses Tests: Full Dataset}

We test our hypotheses on the entire dataset by examining the structural model. We also conduct

\footnotetext{
${ }^{4}$ The exceptions are item 1 of PRESSpeers and item 3 of PRESSform. We did not delete these items since they loaded well in the previous factor analysis. Moreover, the Cronbach's (1951) alphas of the constructs do not improve if these items are deleted.
} 


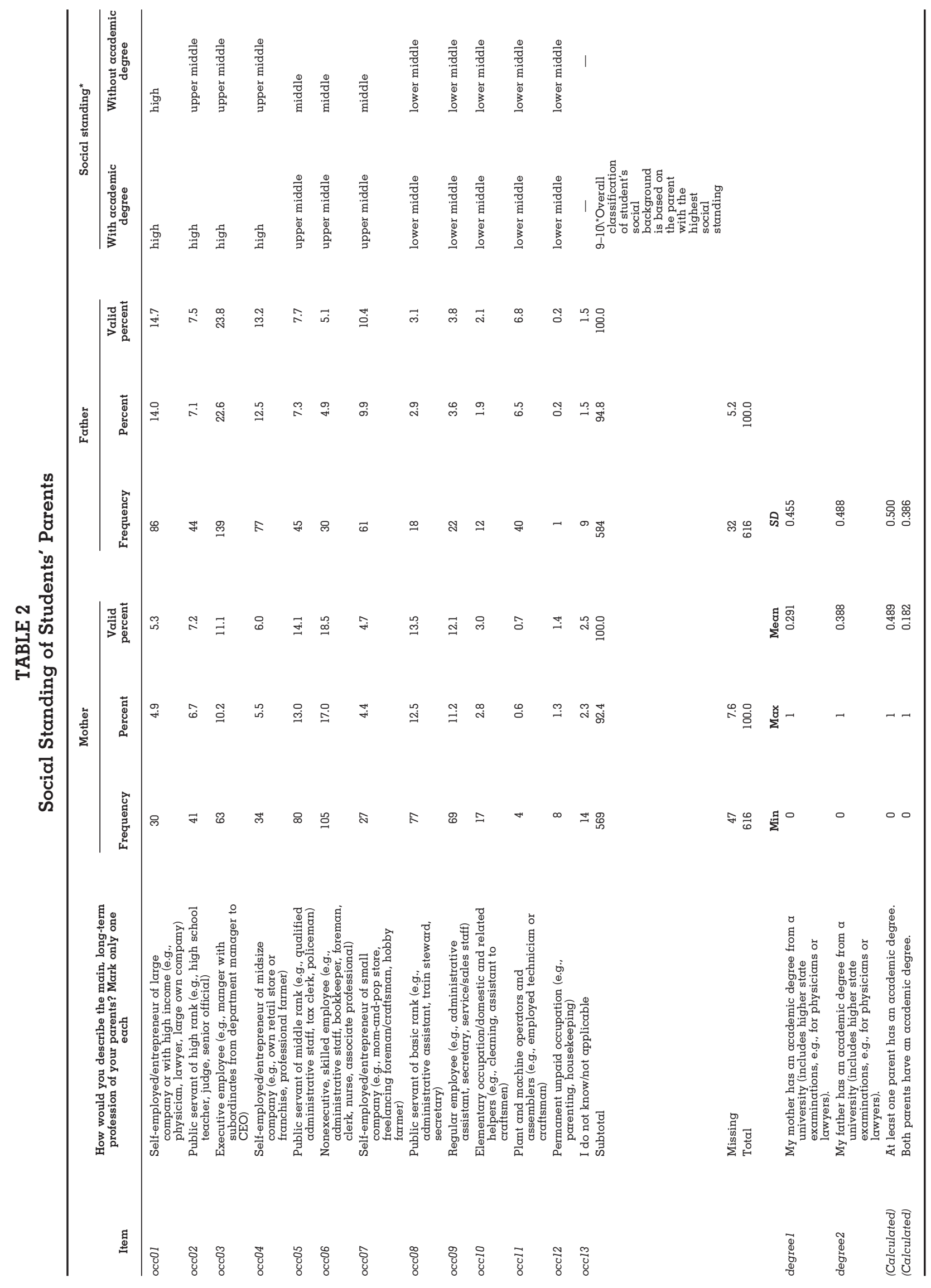


TABLE 3

Social Background of Students by Gender

\begin{tabular}{|c|c|c|c|c|c|}
\hline & \multicolumn{4}{|c|}{ Social background of students } & Total \\
\hline Female & $29(7.7 \%)$ & $71(18.8 \%)$ & $112(29.7 \%)$ & $165(43.8 \%)$ & $377(100.0 \%)$ \\
\hline Total & $54(8.8 \%)$ & $111(18.0 \%)$ & $195(31.7 \%)$ & $256(41.6 \%)$ & $616(100.0 \%)$ \\
\hline
\end{tabular}

Note. Values in parentheses are percentages.

Pearson chi-square test is not significant (3.940, $d f=3$, Asymp. Sig. 2-sided $=0.268$ ).

exploratory analyses of our model using six subsamples of the data, which consist of the four social background categories and the two sexes. Because PLS maximizes the variance explained, the $R^{2}$ is the appropriate criterion for evaluation of overall model fit (Barclay et al., 1995; Chin, 1998). In addition, we use the Stone-Geisser $Q^{2}$ test to assess the predictive validity of our parameter estimates (Geisser, 1974; Stone, 1974). ${ }^{5}$ The standardized path coefficients $(\beta \mathrm{s})$ for each construct can be interpreted as in an OLS regression. Because PLS does not make any assumptions about the distribution of the data, it requires bootstrapping to determine the statistical significance of each path coefficient (Chin, 1998). We perform the usual 1,000 draws with replacement. Our model explains $27.5 \%$ of the variance $\left(R^{2}\right)$ in EMI choice. Table 6 reports the results from the full sample.

We do not observe a direct association between BACKGROUND and EMI $(\beta=-0.013 ; p>.1)$ or between JOBADVANTAGE and EMI $(\beta=0.012$; $p>.1)$, which lets us reject Hla and Hlc. Hlb and Hld predict that a student's social background has a positive relationship with the expectation of English as the working language and with English proficiency, respectively. The coefficients are positive and statistically significant $(\beta=0.142 / 0.143$; $p<.001 / .001)$. Thus, we find support for $\mathrm{Hlb}$ and Hld.

We propose that students who expect that English will be (partly) their working language (JOBNEED) will choose EMI (H2a) and see an advantage for their future career from choosing EMI (H2b). The results from our model do not support a direct link between JOBNEED and EMI ( $\beta=0.016$; $p>.1)$, indicating that even students who realize the overall importance of English for the labor mar-

\footnotetext{
${ }^{5}$ Values range from -1 to +1 . Positive values indicate predictive validity.
}

ket do not act upon their insight by choosing EMI. Hence, we reject H2a. Nevertheless, the model shows that there is a moderately strong but highly significant link between JOBNEED and JOBADVANTAGE $(\beta=0.380 ; p<.001)$. So students who realize the importance of English for employment on a global scale tend to draw consistent conclusions about their own employability. Therefore, we accept H2b.

For JOBADVANTAGE, we also propose that students who realize the importance of English for their individual careers choose EMI. The positive and highly significant effect $(\beta=0.218 ; p<.001)$ suggests accepting H3.

H4a states that English proficiency (ENGLISH) has a positive effect on the choice of EMI. It is notable that we have to reject $\mathrm{H} 4 \mathrm{a}(\beta=0.055$; $p>.1)$. On the contrary, we find clear support for H4b $(\beta=-0.411 ; p<.001)$, which suggests that $\alpha$ higher level of English proficiency lowers the expected BARRIERS to choosing EMI. This result demonstrates that even students who assess their English skills as excellent are not motivated by this fact to choose EMI. Their confidence in their English proficiency only lowers the barriers that prevent them from choosing EMI. ${ }^{6}$

We assert that students who expect the BARRIERS to EMI to be high self-select against EMI. Based on the full model, we find support for H5 $(\beta=-0.275 ; p<.001)$.

The only control variable that is statistically significant in the full model is PRESSpeers $(\beta=0.223$; $p<.001)$. This suggests that choosing EMI is significantly related to peers' attitudes toward EMI.

We use Cohen's (1988) $f^{2}$ statistic to assess the effect size of the independent constructs on the dependent constructs. The test assesses the

\footnotetext{
${ }^{6}$ We confirmed the robustness of all mediation effects (Burkert, Davila, Mehta, \& Oyon, 2013).
} 


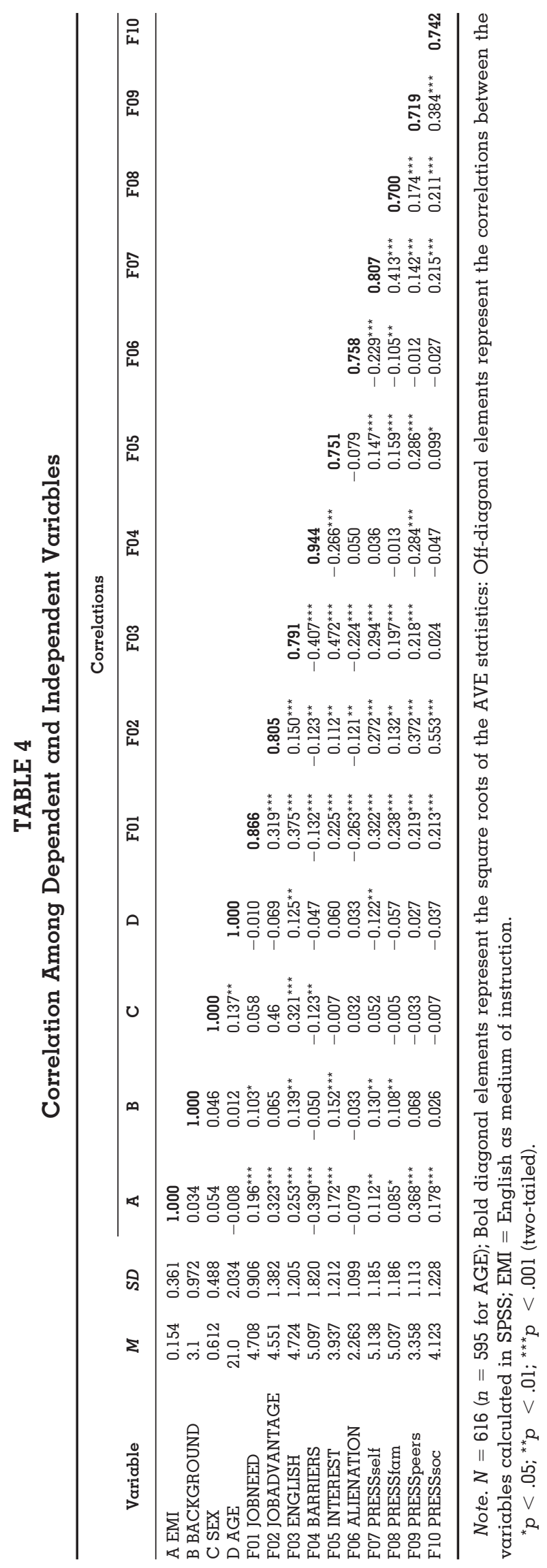


TABLE 5

Construct Reliability and Descriptive Statistics

\begin{tabular}{clccc}
\hline No. & \multicolumn{1}{c}{ Factor } & $\begin{array}{c}\text { Cronbach's } \\
\text { alpha }\end{array}$ & $\begin{array}{c}\text { Composite } \\
\text { reliability }\end{array}$ & AVE \\
\hline 1 & JOBNEED & 0.888 & 0.923 & 0.750 \\
2 & JOBADVANTAGE & 0.860 & 0.901 & 0.648 \\
3 & ENGLISH & 0.897 & 0.920 & 0.625 \\
4 & BARRIERS & 0.938 & 0.961 & 0.890 \\
5 & INTEREST & 0.739 & 0.835 & 0.564 \\
6 & ALIENATION & 0.843 & 0.870 & 0.574 \\
7 & PRESSself & 0.826 & 0.881 & 0.651 \\
8 & PRESSfam & 0.770 & 0.822 & 0.490 \\
9 & PRESSpeers & 0.647 & 0.742 & 0.517 \\
10 & PRESSsoc & 0.725 & 0.828 & 0.550 \\
\hline
\end{tabular}

Note. $N=616$. AVE $=$ average variance extracted.

difference in the explained variance when on independent variable is excluded. The effect size is defined as $f^{2}=\left(R^{2}{ }_{\text {incl. }}-R^{2}{ }_{\text {excl. }}\right) /\left(1-R^{2}{ }_{\text {incl. }}\right)$ (Cohen, 1988: 410). The results above $0.02,0.15$, and 0.35 respectively indicate small, medium, and large effect sizes in the model. As depicted in Table 6, the Cohen's $f^{2} s$ indicate small size effects for BARRIERS, JOBADVANTAGE and PRESSpeers. BACKGROUND, ENGLISH and JOBNEED exhibit medium-sized effects and constitute the main predictors of students' EMI choices. While having excellent English skills and recognizing their importance for highly qualified labor seem to be obvious determinants of choosing EMI, the medium-sized effect of BACKGROUND uncovers and highlights the hidden mechanisms of power in the field through habitus and cultural capital. This finding is of particular value: Our model demonstrates that this effect is not directly observable because we reject Hla. ${ }^{7}$

\section{Further Analyses: \\ Social Background and Sex}

The following six analyses use the same model as in the previous section. The first four analyses

\footnotetext{
${ }^{7}$ A simple $t$ test confirms the medium size effect of BACKGROUND on EMI choice. Based on Table 8, we combine students from strata 1 and 2 that have chosen EMI (11.5\%, i.e., 19 of 165 ) and compare them to the students from strata 3 and 4 (16.9\%, i.e., 76 of 451$)$. Overall, the students from the higher strata choose EMI almost $50 \%$ more often than the lower strata. This difference is significant at $p<0.1$.
}

evaluate the full model according to the four social background categories of the students. ${ }^{8}$

\section{Social Backgrounds}

Stratifying the full dataset into the social background categories $1-4$ ( $1=$ lower middle, $2=$ middle, $3=$ upper middle, and $4=$ high) reveals further insights. We report the results of all four models in Table 7.

We observe that the $R^{2}$ of EMI remains stable for subsample 4 (high) and increases for all other subsamples, reaching a high $R^{2}$ of $65.1 \%$ for subsample 1 (lower middle).

Because BACKGROUND is homogeneous within each subsample, Table 7 does not contain information on the pertinent path coefficients used to test Hla-d. With respect to H2a-b, H4a-b, and H5, we observe almost no differences from the previously presented full model, which speaks to the robustness of our previous hypothesis tests. Closer examination of $\mathrm{H} 3$ does, however, reveal an interesting finding: Students from the lower middle background (stratum 1) do not choose EMI even if they understand its benefits $(\beta=0.004 ; p>.1)$.

Analyses of the control variables offer further fruitful insights into the motivation of students' EMI choice. The subsamples reveal that PRESSpeers is a decisive factor for students irrespective of social background. Nevertheless, PRESSpeers steadily increases in both strength and significance from students with a high social background $(\beta=0.170 ; p<.05)$ to the lower middle social background $(\beta=0.450 ; p<.01)$. These results indicate that the attitude of peers toward EMI is a substantially stronger determinant of EMI choice for students from the lower middle background than for students from the high background.

Another remarkable background-specific difference relates to the sex of the students. In stratum 2 (middle), 9.9\% of the females chose EMI, but only $2.5 \%$ of the males did so. In stratum 1 (lower middle), just $8.0 \%$ of the males chose EMI compared to $31 \%$ of the females; this was the highest observed value in the dataset across all strata. We analyze the full model for sex-specific differences in the next section.

\footnotetext{
${ }^{8}$ Inevitably, this means that the first 4 models cannot employ the variable BACKGROUND because the variable is constant in each subsample. Likewise, the two analyses stratified by SEX employ all variables from the full model except for SEX.
} 
TABLE 6

PLS Structural Model Results-Full Dataset

\begin{tabular}{|c|c|c|c|c|c|c|c|}
\hline \multirow[b]{2}{*}{ Hypotheses } & \multirow{2}{*}{$\begin{array}{l}\text { Independent } \\
\text { variables }\end{array}$} & \multicolumn{6}{|c|}{ Dedependent variables } \\
\hline & & EMI & JOBNEED & JOBADVANTĀGE & ENGLISH & BARRIERS & Cohen's $f^{2}$ \\
\hline Hla-d & BACKGROUND & $-0.013[\mathrm{Hla}](0.352)$ & 0.142 [Hlb] $(3.369)^{*}$ & $0.012[\mathrm{Hlc}](0.290)$ & $0.143[\mathrm{Hld}](3.448)^{*}$ & - & 0.23 \\
\hline $\mathrm{H} 2 \mathrm{a}-\mathrm{b}$ & JOBNEED & $0.016[\mathrm{H} 2 \mathrm{a}](0.399)$ & - & $0.380[\mathrm{H} 2 \mathrm{~b}](10.410)^{*}$ & - & - & 0.16 \\
\hline H3 & JOBADVANTAGE & 0.218 [H3] $(5.081)^{\star}$ & - & - & - & - & 0.04 \\
\hline $\mathrm{H} 4 \mathrm{a}-\mathrm{b}$ & ENGLISH & $0.055[\mathrm{H} 4 \mathrm{\alpha}](1.241)$ & - & - & - & $-0.411[\mathrm{H} 4 \mathrm{~b}](11.472)^{\star}$ & 0.24 \\
\hline \multirow[t]{10}{*}{ H5 } & BARRIERS & $-0.275[\mathrm{H} 5](6.480)^{\star}$ & - & - & - & - & 0.08 \\
\hline & INTEREST & $-0.028(0.614)$ & - & - & - & - & 0.00 \\
\hline & ALIENATION & $-0.020(0.430)$ & - & - & - & - & 0.00 \\
\hline & PRESSself & $0.002(0.037)$ & - & - & - & - & 0.00 \\
\hline & PRESSfam & $0.008(0.210)$ & - & - & - & - & 0.00 \\
\hline & PRESSpeers & $0.223(4.992)^{*}$ & - & - & - & - & 0.05 \\
\hline & PRESSsoc & $-0.037(0.870)$ & - & - & - & - & 0.00 \\
\hline & SEX & $-0.004(0.102)$ & - & - & - & - & 0.00 \\
\hline & AGE & $-0.009(0.239)$ & - & - & - & - & 0.00 \\
\hline & $R^{2}$ & 0.275 & 0.020 & 0.146 & 0.020 & 0.169 & \\
\hline
\end{tabular}

Note. $N=616$. Path coefficient (and $t$ values) are reported for every tested path in the PLS model.

${ }^{*} p<0.001$

\section{Sex}

We analyze the model based on subsamples of male and female respondents. The $R^{2}$ of EMI remains stable for the female subsample $\left(R^{2}=28.4 \%\right)$ and increases for the male subsample $\left(R^{2}=33.3 \%\right)$. There are only small sex-specific differences relating to Hla, H4a-b, and H5, which do not contradict our previous hypotheses tests. We report the results of all four models in Table 9.

Concerning the effect of BACKGROUND (Hla), we find that there are very small and weakly significant effects on the choice of EMI for males and females $(\beta=0.079 /-0.076 ; p<.1 / 0.05)$. Males from higher strata tend to choose EMI, while females from lower strata tend to choose EMI.

Another very small $(\beta=0.082)$ and practically nonsignificant effect $(p<.1)$ that differs from the full model is that the construct English has a slight direct influence on the choice of EMI (H4a). This might relate to the higher-most likely genderedassessments that females make of their English skills. Moving from strata $1-4$, females rate their skills on the 7-point Likert scale as 4.6; 4.9; 5.0; and 5.1. The corresponding males assess their skills as only $4.0 ; 3.9 ; 4.3$; and 4.4 (data not shown). The females from the lowest social background assess their English skills at a higher level than the males from the highest social background. The same level of skills in English gives males more confidence than females (H4b). As a result, the former believe that the barriers to choosing EMI are lower. The coefficient for males is approximately $50 \%$ higher and has a much higher $t$ value compared to the coefficient for females $(\beta=-0.490 /-0.324$; $p<.001 / 0.001)$. Yet, when faced with the same barriers (H5), males are less likely than females to choose EMI, as indicated by the negative coefficients $(\beta=-0.395 /-0.214 ; p<.001 / 0.001)$.

\section{DISCUSSION}

We investigate why non-native English language speakers choose EMI. Our study contributes to both theory and practice.

\section{Contributions to Theory and Methodology}

In relation to Bourdieu's theory, we empirically demonstrate that social background substantially affects the choice of EMI through the mediating "hidden mechanisms" (Swartz, 1997: 261) of cultural capital (language) and habitus (sense of place in the academic field). Students opt against EMI because they believe that the English language poses a barrier to their goals, for example, they fear receiving lower grades (less institutionalized cultural capital) or missing content in lectures (less cultural capital). Lower-strata students perceive the barriers to EMI as much higher than they actually are. We demonstrate that all students in the EMI/DMI programs have outstanding English proficiency, but that a higher social background is systematically related to higher levels of perceived English proficiency ("linguistic capital," Bourdieu, 1991: 57). The higher- (lower-) strata students' tendency to opt for (against) EMI thus 


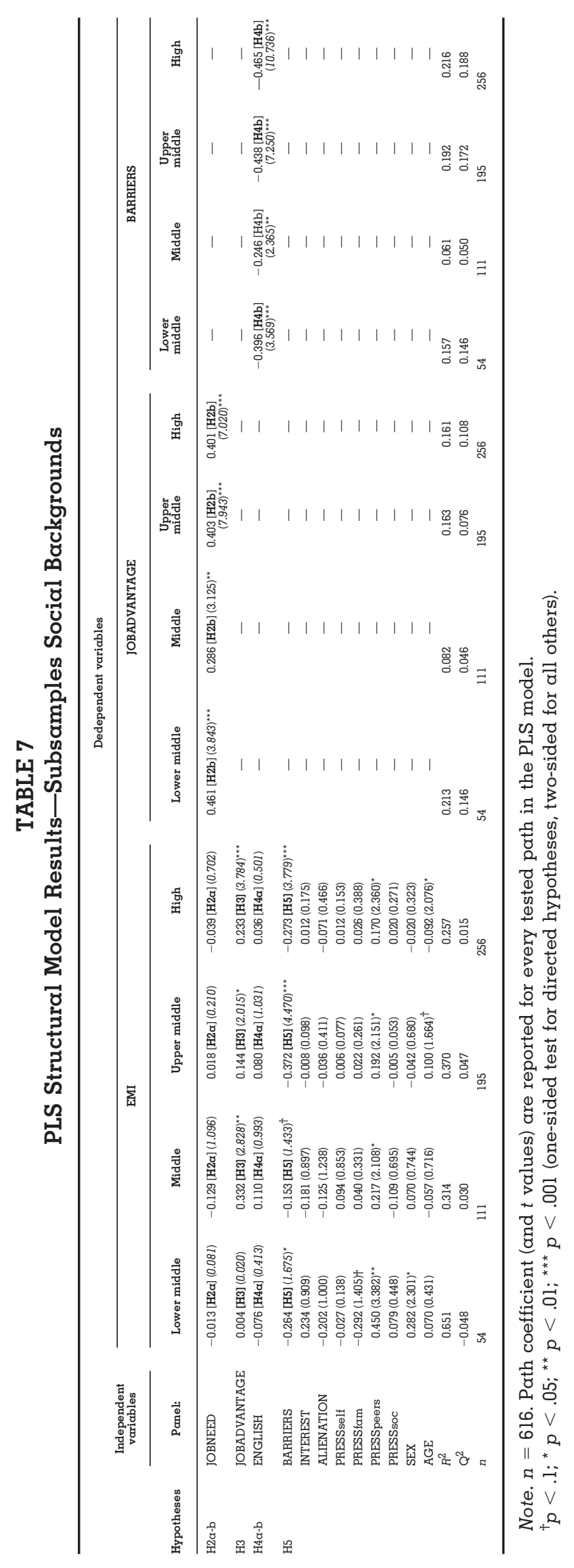


TABLE 8

Descriptive Cross Table of EMI Choice (Social background $\times$ Sex)

\begin{tabular}{|c|c|c|c|c|c|c|c|c|c|}
\hline \multirow[b]{2}{*}{ Stratum } & \multicolumn{3}{|c|}{ Total $(N=616)$} & \multicolumn{3}{|c|}{ Male $(n=239)$} & \multicolumn{3}{|c|}{ Female $(n=377)$} \\
\hline & DMI & EMI & All & DMI & EMI & All & DMI & EMI & All \\
\hline 2 (middle) $(n=111)$ & $103(92.8 \%)$ & $8(7.2 \%)$ & 111 & $39(97.5 \%)$ & $1(2.5 \%)$ & 40 & $64(90.1 \%)$ & $7(9.9 \%)$ & 71 \\
\hline 3 (upper-middle) $(n=195)$ & $162(83.1 \%)$ & $33(16.9 \%)$ & 195 & $71(85.5 \%)$ & $12(14.5 \%)$ & 83 & $91(81.3 \%)$ & $21(18.8 \%)$ & 112 \\
\hline 4 (high) $(n=256)$ & $213(83.2 \%)$ & $43(16.8 \%)$ & 256 & $75(82.4 \%)$ & $16(17.6 \%)$ & 91 & $138(83.6 \%)$ & $27(16.4 \%)$ & 165 \\
\hline
\end{tabular}

Note. DMI = Danish as medium of instruction; EMI = English as medium of instruction.

reflects their doxical field correspondence and not necessarily their capabilities. We contribute a set of constructs that make these "hidden mechanisms" visible through quantitative analysis.

The constructs capture the dialectic relationship between agency and social context in one model, representing Bourdieu's reciprocal "structured structures" and "structuring structures" (Bourdieu, 1990c: 53). We thereby offer a conceptual alternative to self-efficacy measures of scholarly success. Still, to investigate the relevance of choice at the level of the agent we suggest integrating selfefficacy into the future application of Bourdieusian theory. With our empirical focus on language choice within management education, we contribute to exploring the role of language as a social mediator between behavior and social structure. Since language represents institutionalized cultural and symbolic capital, we emphasize that the unmindful implementation of EMI can foster the uneven allocation of additional capital, the dogmatic "recognition of the legitimate language" (Bourdieu, 1991: 49), and the reproduction of a culturally privileged milieu. To transfer theory into higher education proctice, we interpret our findings within the frome of Bourdieu's (1979a: 76) "truly rational pedagogy" (see, "Contributions to Practice").

Moreover, we respond to the call for more research on the globalization of management education by addressing the underexplored role of EMI (Doh, 2010). Given our finding, that EMI will-even at the undergraduate level-function as a distinction for higher-strato students with on interest in social and symbolic capital, we also contribute to critical management studies.

Finally, we point to the underexplored role of gender in Bourdieu's work. The (statistically weak) finding that females from the lower strata are so surprisingly confident in their English skills and their EMI choice invites debate over whether future research should treat gender as a secondary constituent of social class as in our study or as a fundamental division in society (Bourdieu, 1984: 468). The latter division would conflict with Bourdieu's elaborations on the connections among capital, gender, symbolic violence, and the hysteresis effect of position and disposition (Bourdieu, 1990b, 2003a). Women adapt their dispositions to their objective-and limited-opportunities, thereby following the logic of "amor fati" (Bourdieu, 1990b: 13). Yet, the "negative capital of femaleness" (Djerf-Pierre, 2005: 265) can, under certain circumstances, be counterbalanced by gendered language-learning motivation and skills (Akram \& Ghani, 2013; Daif-Allah, 2012).

\section{Contributions to Practice}

As to public policy, we conjecture that globalizing management education is the sole feasible alternative for the leading universities (Doh, 2010), and that EMI is an effective tool for this internationalization. But, first, we caution that how EMI is implemented is crucial for its success as a language of choice and for the achievement of equal chances. Our findings on the strata-specific perception of barriers should alert policy makers that higher levels of English proficiency per se will not lead to greater acceptance of EMI among students in the lower strata. Universities can embrace the opportunity that undergraduate students arecompared to many MBA students-mainly interested in the content of the program (the cultural capital). With regards to the perceived language barriers of lower-strata students, policy makers should allay these students' concerns about the difficulty of EMI programs and take action to help students overcome the perceived barriers ("reflexive practice," see Maclean et al., 2012). This could 


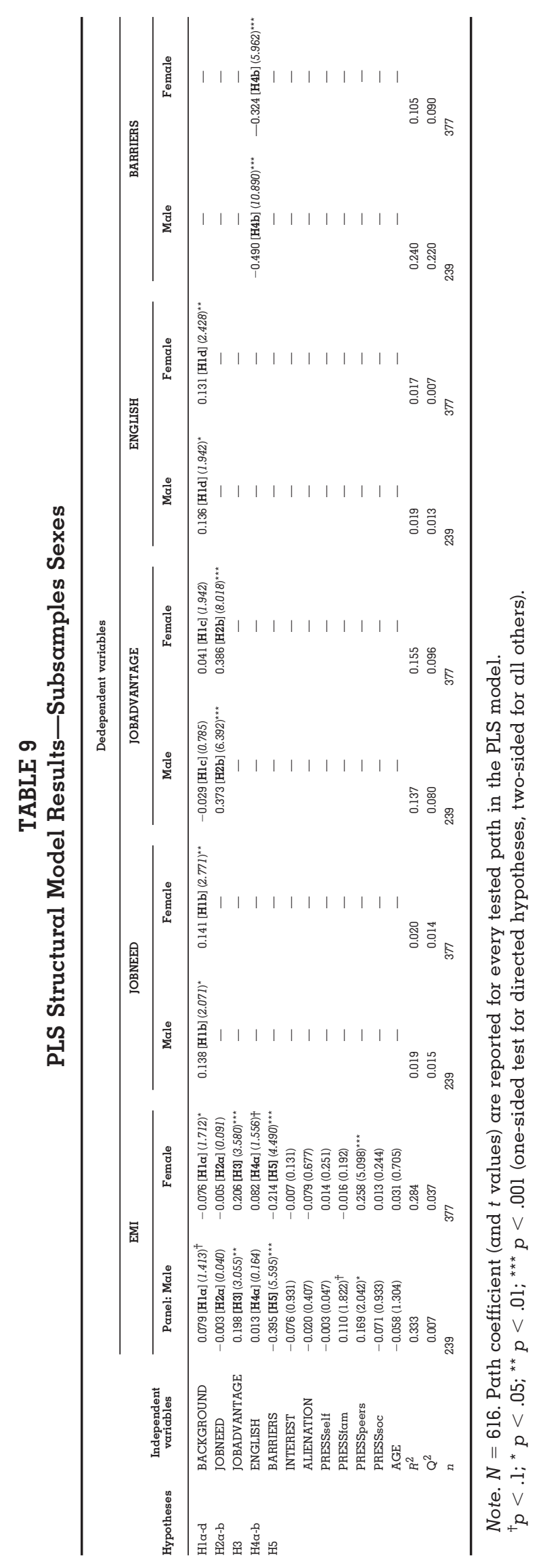


also lower right-wing political resistance to such programs among those who feel that their domestic capital has been devalued. Examples of lowering barriers could include practice days, mandatory internships, or active relationships with alumni. In line with Bourdieu's "rational pedagogy"-which requires that assignments reflect the students' content-related work rather than their rhetorical and linguistic abilities (Baudelot, 1994; Bourdieu \& Passeron, 1977)-lecturers and course administrators must stress in their course descriptions that the comprehensibility of the students' English is more important than their adeptness on English-language exams.

Second, the integration of more students into EMI programs provides economies of scale for these programs and might help to find the resources to embed local traditions within a globalized education (Mazza, Sahlin-Andersson, \& Pedersen, 2005). For instance, it might become feasible to translate Continental European business traditions into English instead of simply importing Anglo-American content for a small number of students.

Third, our findings are equally valuable for Anglo-American universities that attempt to attract non-native English speakers from abroad (e.g., Zheng, 2004).

\section{Limitations and Future Research}

The limitations of our work provide avenues for future research. First, we caution against generalizing our findings beyond the context of higher education in management. Future research may find that the effects presented here are more pronounced in more socially stratified contexts. Although Denmark's educational system is not fully socially inclusive (Orr et al., 2011), Denmark has one of the lowest growing income inequality (GINI) coefficients worldwide (OECD, 2011). The higher levels of inequality in (most) other European countries imply that students with inappropriate institutionalized cultural capital have higher chances of dropping out. Furthermore, the English language may be an even stronger social separator in countries where the perceived English proficiency is lower than in Denmark and student selection is biased toward the socially advantaged (e.g., Germany, France, Italy, Turkey; see Clayton, 2006; European Commission, 2006; Orr et al., 2011). The subsequent devaluation of the domestic language program contributes to further division. Class is- sues have especially been problematic in some Asian regions where expensive tuition and supplementary education in the English language (e.g., a stay abroad) are needed to keep up with the recent shift to EMI (Jeong, 2004; Kang, 2012).

Second, we have neither used constructs on general self-efficacy (Schwarzer \& Jerusalem, 1995) nor implemented a scale for measuring perceived selfefficacy for EMI. Follow-up studies could use these constructs as mediating variables to understand the process of doxa in depth. These TPB (theory of planned behavior) elements would be a step toward explaining the importance of peer pressure and sex that might have their roots in a class- and gender-specific sensitivity toward normative beliefs, subjective norms, and self-efficacy. Our study could also be extended using social network analysis (Scott, 2003) to identify the agents in the field that actually have the power to declare that the English language is symbolic capital.

Third, the development of EMI choice could be assessed using longitudinal data to examine the potential effects of government or university interventions. Gathering such data would be facilitated if researchers created constructs for Bourdieu's types of capital and habitus based on publicly available data. In addition, the longitudinal perspective would help to close the gap between the antecedents of educational attainment (Bourdieusian theory) and its organizational outcomes (upper-echelon theory; Finkelstein \& Hambrick, 1996; Ott, 2011).

Fourth, the proficiency of English among Danish students is so high that our findings might not be generalizable to settings with lower proficiency, such as Asia (Evans \& Green, 2007). To understand if a choice in itself is a perpetuator of unequal chances, it would be helpful to examine whether the reported problems with mandatory EMI in Asia (Kang, 2012) can be prevented by measures such as free additional language classes, a shift toward student-centered learning (Gao, 2012), or a clear subordination of language to content requirements.

\section{CONCLUSIONS}

Our study provides insights from an exceptional, multilingual Danish setting and develops constructs for future research. It uncovers the mediating effects of cultural capital and habitus in the relationship between social background and the choice of EMI in management education. 
Our work must not be interpreted as opposing EMI in higher education. Abandoning EMI would be to the detriment of students, higher education, and possibly the broader economy because students generally see EMI as a personal enrichment and as a boon for their future careers. Instead, we contribute to the debate on class sensitivity in management education, which suggests that the diffusion of EMI be accompanied by policies that dismantle the barriers that lower-strata students perceive as prohibitive. This differs substantially from the politically exploitable dispute on domestic language protection or cultural imperialism.

We hope to contribute to a better understanding of the ways in which higher education in management plays a role in the (re-)production of privilege and disadvantage and to add to the current debates on EMI and social equality in management education.

\section{REFERENCES}

Aarhus University. 2012. Internationalisation Strategy. Retrieved from http://www.au.dk/fileadmin/www.au.dk/ om_au/profil/informationsmateriale/internationaliserings strategi_2009-2013/internationalisationstrategy.pdf. Accessed on 20 June 2012.

Abedi, J., \& Lord, C. 2001. The language factor in mathematics tests. Applied Measurement in Education, 14: 219-234.

Adshead, L., \& Jamieson, A. 2008. Educational decision-making: Rationality and the impact of time. Studies in the Education of Adults, 40: 143-159.

Ajzen, I. 1985. From intentions to actions: A theory of planned behavior. In J. Kuhl \& J. Beckman (Eds.), Action-control: From cognition to behavior: 11-39. Heidelberg: Springer.

Ajzen, I. 1991. The theory of planned behavior. Organizational Behavior and Human Decision Processes, 50: 179-211.

Ajzen, I., \& Fishbein, M. 2005. The influence of attitudes on behavior. In D. Albarracín, B. T. Johnson \& M. P. Zanna (Eds.), The handbook of attitudes: 173-222. Mahwah, NJ: Lawrence Erlbaum Associates.

Ajzen, I., \& Madden, T. J. 1986. Prediction of goal-directed behavior: Attitudes, intentions, and perceived behavioral control. Journal of Experimental Social Psychology, 22: 453-474.

Akram, M., \& Ghani, M. 2013. Gender and language learning motivation. Academic Research International, 4: 536-540.

Ammon, U., \& McConnell, G. 2002. English as an academic language in Europe: $A$ survey of its use in teaching. Bern: Peter Lang.

Andrade, M. S. 2009. The effects of English language proficiency on adjustment to university life. International Multilingual Research Journal, 3: 16-34.

Araque, F., Roldón, C., \& Salguero, A. 2009. Factors influencing university drop out rates. Computers and Education, 53: 563-574.
Ball, R., \& Chik, R. 2001. Early employment outcomes of home and foreign educated graduates-The Malaysian experience. Higher Education, 42: 171-189.

Bandura, A. 1993. Perceived self-efficacy in cognitive development and functioning. Educational Psychologist, 28: 117148.

Bandura, A. 2001. Social cognitive theory: An agentic perspective. Annual Review of Psychology, 52: 1-26.

Barclay, D., Thompson, R., \& Higgins, C. 1995. The partial least squares (PLS) approach to causal modelling: Personal computer adoption and use as an illustration. Technology Studies, 2: 285-309.

Baudelot, C. 1994. Student rhetoric in exams. In P. Bourdieu, J.-C. Passeron \& M. d. Saint Martin (Eds.), Academic discourse: 80-94. Cambridge: Polity Press.

Bedeian, A. G. 2007. Even if the tower is "ivory," it isn't "white:" Understanding the consequences of faculty cynicism. Academy of Management Learning and Education, 6: 9-32.

Belloc, F., Maruotti, A., \& Petrella, L. 2010. University drop-out: An Italian experience. Higher Education, 60: 127-138.

Bennett, R. 2003. Determinants of undergraduate student drop out rates in a university business studies department. Journal of Further and Higher Education, 27: 123-141.

Bisbe, J., Batista-Foguet, J.-M., \& Chenhall, R. 2007. Defining management accounting constructs: A methodological note on the risks of conceptual misspecification. Accounting, Organizations and Society, 32: 789-820.

Boardman, J. D., \& Robert, S. A. 2000. Neighborhood socioeconomic status and perceptions of self-efficacy. Sociological Perspectives, 43: 117-136.

Bourdieu, P. 1971. Intellectual field and creative project. In M. F. D. Young (Ed.), Knowledge and control: New directions for the sociology of education: 161-188. London: CollierMacMillan.

Bourdieu, P. 1975. The specificity of the scientific field and the social conditions of the progress of reason. Social Science Information, 14: 19-47.

Bourdieu, P. 1977a. The economics of linguistic exchanges. Social Science Information, 16: 645-668.

Bourdieu, P. 1977b. Outline of a theory of practice. Cambridge: Cambridge University Press.

Bourdieu, P. 1979a. The inheritors: French students and their relation to culture. Chicago: University of Chicago Press.

Bourdieu, P. 1979b. Symbolic power. Critique of Anthropology, 4: 77-85.

Bourdieu, P. 1984. Distinction: A social critique of the judgement of taste. Cambridge: Harvard University Press.

Bourdieu, P. 1989. Social space and symbolic power. Sociological Theory, 7: 14-25.

Bourdieu, P. 1990a. In other words: Essays towards a reflexive sociology. Stanford, CA: Stanford University Books.

Bourdieu, P. 1990b. La domination masculine. Actes de la Recherche en Sciences Sociales: 2-31.

Bourdieu, P. 1990c. The logic of practice. Stanford: Stanford University Books. 
Bourdieu, P. 1991. Language and symbolic power. Cambridge, MA: Harvard University Press.

Bourdieu, P. 1996. The state nobility. Elite schools in the field of power. Cambridge: Polity Press.

Bourdieu, P. 1997. The forms of capital. In A. H. Halsey, H. Lauder, P. Brown \& A. S. Wells (Eds.), Education, culture, economy, society: 46-58. Oxford: Oxford University Books.

Bourdieu, P. 1998. Practical reason: On the theory of action. Stanford, CA: Stanford University Books.

Bourdieu, P. 2003a. À propos de la domination masculine. Revue Agone, 28: 73-86.

Bourdieu, P. 2003b. Participant objectivation. Journal of the Royal Anthropological Institute, 9: 281-294.

Bourdieu, P. 2005. The social structures of the economy. Cambridge: Polity Press.

Bourdieu, P., \& Passeron, J. C. 1977. Reproduction in education, society and culture. London: Sage.

Bourdieu, P., \& Passeron, J. C. 1994. Introduction: Language and relationship to language in the teaching situation. In P. Bourdieu, J. C. Passeron \& M. d. Saint Martin (Eds.), Academic discourse: 1-34. Cambridge: Polity Press.

Bourdieu, P., Passeron, J.-C., \& Saint Martin, M. d. 1994a. Academic discourse. Cambridge: Polity Press.

Bourdieu, P., Passeron, J.-C., \& Saint Martin, M. d. 1994b. Students and the language of teaching. In P. Bourdieu, J.-C. Passeron \& M. d. Saint Martin (Eds.), Academic discourse: 35-79. Cambridge: Polity Press.

Brislin, R. W., Lonner, W. J., \& Thorndike, R. M. 1973. Crosscultural research methods. New York: John Wiley \& Sons.

Burke, N. J., Bird, J. A., Clark, M. A., Rakowski, W., Guerra, C., Barker, J. C., \& Pasick, R. J. 2009b. Social and cultural meanings of self-efficacy. Health Education and Behavior, 36(Suppl. 5): 111S-128S.

Burkert, M., Davila, A., Mehta, K., \& Oyon, D. 2014. Relating alternative forms of contingency fit to the appropriate methods to test them. Management Accounting Research, 25 (1): 6-29.

Burkert, M., \& Lueg, R. 2013. Differences in the sophistication of Value-based Management-The role of top executives. Management Accounting Research, 24: 3-22.

Byun, K., Chu, H., Kim, M., Park, I., Kim, S., \& Jung, J. 2011. English-medium teaching in Korean higher education: Policy debates and reality. Higher Education, 62: 431-449.

Chin, W. W. 1998. The partial least squares approach to structural equation modelling. In G. A. Marcoulides (Ed.), Modern methods for business research: 295-336. Mahwah, NJ: Lawrence Erlbaum.

Christensen, M. K. 2009. The language of instruction at Danish universities. In P. Harder (Ed.), English in Denmark: Language policy, internationalization and university teaching: 9: 58-67. Copenhagen: Museum Tusulanum Press. University of Copenhagen.

Clachar, A. 1997. Resistance to the English language in Puerto Rico: Toward a theory of language and intergroup distinctiveness. Linguistics and Education, 9: 69-98.
Clayton, T. 2006. Language choice in a nation under transition. English language spread in Cambodia. New York: Springer.

Clemente, A. 2007. English as cultural capital in the Oaxacan community of Mexico. TESOL Quarterly, 41: 421-425.

Cohen, J. 1988. Statistical power analysis for the behavioral sciences. Hillsdale, NJ: Lawrence Erlbaum Associates.

Coleman, J. A. 2004. The language of higher education. Language and the future of Europe: Ideologies, policies and practices. UK Centre for Transnational Studies: University of Southampton.

Coleman, J. A. 2006. English-medium teaching in European higher education. Language Teaching, 39: 1-14.

Costa, F., and Coleman, J. A., Bialystok, E. 2012. A survey of English-medium instruction in Italian higher education. International Journal of Bilingual Education and Bilingualism 2012:1-17.

Cronbach, L. J. 1951. Coefficient alpha and the internal structure of tests. Psychometrika, 16: 297-334.

Daif-Allah, A. S. 2012. Beliefs about foreign language learning and their relationship to gender. English Language Teaching, 5: 20-33.

Danish Ministry of Science, Innovation and Higher Education. 2012. Studyindenmark. Copenhagen: Danish Ministry of Science, Innovation and Higher Education.

Diab, R. L. 2006. University students' beliefs about learning English and French in Lebanon. System, 34: 80-96.

Djerf-Pierre, M. 2005. Lonely at the top: Gendered media elites in Sweden. Journalism, 6: 265-290.

Doh, J. P. 2010. From the editors: Why aren't business schools more global and what can management educators do about it? Academy of Management Learning and Education, 9: 165-168.

Educational Testing Service (ETS). 2011. Test and Score Data Summary for TOEFL Internet-Based and Paper-Based Tests: January 2010-December 2010 Test Data. Princeton, NJ: ETS.

Elliot, J., \& Knight, J. A. 2005. Student motivation: The bottom line. Agricultural Education Magazine, 77: 8-10.

Engwall, L. 2004. The Americanization of Nordic management education. Journal of Management Inquiry, 13: 109-117.

European Commission. 2006. Europeans and their languages. Special Eurobarometer. Brussels, Belgium: European Commission.

Evans, S., \& Green, C. 2007. Why EAP is necessary: A survey of Hong Kong tertiary students. Journal of English for Academic Purposes, 6: 3-17.

Felix, M. 2006. University and course choice. International Journal of Educational Management, 20: 466-479.

Festing, M., \& Barzantny, C. 2008. A comparative approach to performance management in France and Germany: The impact of the European and the country-specific environment. European Journal of International Management, 2: 208-227.

Finkelstein, S., \& Hambrick, D. C. 1996. Strategic leadership: Top executives and their effects on organizations. Minneapolis/ St. Paul: South-Western. 
Firth, A. 1996. The discursive accomplishment of normality: On "Lingua Franca" English and conversation analysis. Journal of Pragmatics, 26: 237-259.

Fisher, J. D., \& Fisher, W. A. 1992. Changing AIDS-risk behavior. Psychological Bulletin, 11l: 455.

Folkeparti, D. 2009. Arbejdsprogram: Forskningspolitik. Christiansborg: Danske Folkeparti (DF).

Forbes, B., \& Piercy, J. 1991. Corporate mobility and paths to the top. Westport, CT: Quorum.

Fornell, C., \& Larcker, D. F. 1981. Evaluating structural equation models with unobservable variables and measurement error. Journal of Marketing Research, 18: 39-50.

Gao, L. 2012. Digital technologies and English instruction in China's higher education system. Teacher Development, 16: 161-179.

Gardner, R. C. 1985. Social psychology and second language learning: The role of attitudes and motivation. London: Edward Arnold.

Geisser, S. 1974. A predictive approach to the random effect model. Biometrika, 61: 101-107.

Ginsburgh, V., \& Weber, S. 2011. How many languages do we need? The economics of linguistic diversity. Princeton: Princeton University Books.

Going Global. 2006. Denmark career guide 2006: Job-search resources. Mobile, AL: Going Global.

Goodrick, E. 2002. From management as a vocation to management as a scientific activity: An institutional account of a paradigm shift. Journal of Management, 28: 649-668.

Gottlieb, H. 2009. Parallelism or convergence? The English influence on Danish. In P. Harder (Ed.), English in Denmark: Language policy, internationalization and university teaching: 9: 68-94. Copenhagen: Museum Tusculanum.

Hair, J. F., Black, W., Babin, B., \& Anderson, R. E. 2009. Multivariate data analysis (7th ed.). Upper Saddle River, NJ: Pearson/ Prentice Hall.

Harder, P. (Ed.). 2009. English in Denmark: Language policy, internationalization and university teaching (vol. 9). Copenhagen: Museum Tusculanum.

Hinkel, E., (Ed.). 2005. Handbook of research in second language teaching and learning. Mahwah, NJ: Lawrence Erlbaum Associates.

Holme, R., \& Chalauisaeng, B. 2006. The learner as needs analyst: The use of participatory appraisal in the EAP reading classroom. English for Specific Purposes, 25: 403-419.

Hu, G. 2009. The craze for English-medium education in China: Driving forces and looming consequences. English Today, 25: 47-54.

Hu, G., \& Alsagoff, L. 2010. A public policy perspective on English medium instruction in China. Journal of Multilingual and Multicultural Development, 31: 365-382.

Ishida, H., \& Spilerman, S. 2002. Models of career advancement in organizations. European Sociological Review, 18: 179198.

Isserstedt, W., Middendorf, E., Kandulla, M., Borchert, L., \& Leszczensky, M. 2010. Die wirtschaftliche und soziale Lage der Studierenden in der Bundesrepublik Deutschland, 19.
Sozialerhebung des Deutschen Studentenwerks (The economic and social situation of students in the Federal Republic of Germany, the 19th social survey of the German National Association for Student Affairs). Berlin/Bonn: German Federal Ministry of Education and Research (BMBF).

Jacobs, N., \& Harvey, D. 2005. Do parents make a difference to children's academic achievement? Differences between parents of higher and lower achieving students. Educational Studies, 31: 431-448.

Jeong, Y.-K. 2004. A chapter of English teaching in Korea. English Today, 20: 40-46.

Kakh, S. Y., Mansor, W. F. A. W., \& Zakaria, M. H. 2012. English for art communication to enhance quality programs. Procedia Social and Behavioral Sciences, 66: 247-254.

Kang, H.-S. 2012. English-only instruction at Korean universities: Help or hindrance to higher learning? [English]. Today, 28: 29-34.

Kiilo, T., \& Kutsar, D. 2012. When language becomes power: Russian-speaking teachers in the bilingual general education system in Estonia. British Journal of Sociology of Education, 33: 245-262.

Kim, Y., \& Cannella, A. A., Jr.. 2008. Social capital among corporate upper echelons and its impacts on executive promotion in Korea. Journal of World Business, 43: 85-96.

Knight, G., Madsen, T. K., \& Servais, P. 2004. An inquiry into born-global firms in Europe and the USA. International Marketing Review, 21: 645-665.

Kraft, P., Rise, J., Sutton, S., \& Røysamb, E. 2005. Perceived difficulty in the theory of planned behaviour: Perceived behavioural control or affective attitude? British Journal of Social Psychology, 44: 479-496.

Krishnan, V. R. 2008. Impact of MBA education on students' values: Two longitudinal studies. Journal of Business Ethics, 83: 233-246.

Kulturministeriet Denmark. 2003. Sprog på spil - et udspil til den dankse sprogpolitik. Oplæg fra en intern arbejdsgruppe. (Language in jeopardy-A proposal for the Danish language policy. Outline by an internal project team.).Copenhagen: Kulturministeriet Danmark.

Lassibille, G., \& Navarro Gómez, L. 2008. Why do higher education students drop out? Evidence from Spain. Education Economics, 16: 89-105.

Lauer, C. 2002. Enrollments in higher education: Do economic incentives matter? Education and Training, 44: 179-185.

Lee, J. Q., McInerney, D. M., Liem, G. A. D., \& Ortiga, Y. P. 2010. The relationship between future goals and achievement goal orientations: An intrinsic-extrinsic motivation perspective. Contemporary Educational Psychology, 35: 264279.

Louhiala-Salminen, L., Charles, M., \& Kankaanranta, A. 2005. English as a lingua franca in Nordic corporate mergers: Two case companies. English for Specific Purposes, 24: 401421.

Lueg, K., \& Lueg, R. 2012. Why do students choose English as medium of instruction (EMI) in their home country? $A$ sociocultural perspective on non-native speakers. 19th NIC Conference on Intercultural Communication. Aarhus. 
Lueg, K., \& Lueg, R. 2013a. A pragmatic constructivist approach toward higher education management policies: The case of English medium instruction at Aarhus University. Proceedings of Pragmatic Constructivism, (3)2: 87-96.

Lueg, K., \& Lueg, R. 2013b. Why do lingua franca students choose English medium instruction? A Bourdieuian perspective. Proceedings of the 22nd Nordic Academy of Management Conference: 72-73.

Luszczynska, A., Gutiérez-Doña, B., \& Schwarzer, R. 2005. General self-efficacy in various domains of human functioning: Evidence from five countries. International Journal of Psychology, 40: 80-89.

Maclean, M., Harvey, C., \& Chia, R. 2012. Reflexive practice and the making of elite business careers. Management Learning, 43: 385-404.

Maiworm, F., \& Wöchter, B. 2002. English-language-taught degree programmes in European higher education. Bonn: Lemmens.

Maltby, J., Day, L., Giles, D., Gillett, R., Quick, M., LangcasterJames, H., \& Linley, P. A. 2008. Implicit theories of a desire for fame. British Journal of Psychology, 99: 279-292.

Mazza, C., Sahlin-Andersson, K., \& Pedersen, J. S. 2005. European constructions of an American model developments of four MBA programmes. Management Learning, 36: 471-491.

McDonald, M. L., \& Westphal, J. D. 2011. My brother's keeper? CEO identification with the corporate elite, social support among CEOs, and leader effectiveness. Academy of Management Journal, 54: 661-693.

Moen, $\varnothing$., \& Servais, P. 2002. Born global or gradual global? Examining the export behavior of small and medium-sized enterprises. Journal of International Marketing, 10: 49-72.

Muda, N., Ismail, W. R., Shahabudin, F. A., Samsudin, H. B., Suradi, N. R. M., \& Majid, N. 2012. Teaching science and mathematics in English steering mastery in English Language amongst sciences students in UKM. Procedia Social and Behavioral Sciences, 59: 670-677.

Nelson, R. M., \& DeBacker, T. K. 2008. Achievement motivation in adolescents: The role of peer climate and best friends. Journal of Experimental Education, 76: 170-189.

Nunnally, J. C. 1978. Psychometric theory. New York: McGrawHill.

OECD. 2011. Divided we stand. Why inequality keeps rising. An overview of growing income inequalities in OECD countries. Paris: OECD.

Oesch, D. 2006. Coming to grips with a changing class structure: An analysis of employment stratification in Britain, Germany, Sweden and Switzerland. International Sociology, 21: 263-288.

Orr, D., Gwos, C., \& Netz, N. 2011. Social and economic conditions of student life in Europe. Synopsis of indicators. Final report. Eurostudent IV, 2008-2011. Bielefeld: W. Bertelsmann Verlag.

Ott, M. C. 2011. How is postsecondary education associated with membership in the American corporate elite? Ann Arbor: the University of Michigan.

Park, J.-K. 2009. English fever in South Korea: Its history and symptoms. English Today, 25(1): 50-57.
Pedersen, T. 2000. The internationalisation process of Danish firms-Gradual learning or discrete rational choices? Journal of Transnational Management Development, 5: 75-89.

Pennycook, A. 2001. Critical applied linguistics. Mahwah, NJ: Lawrence Erlbaum Associates.

Pishghadam, R., Noghani, M., \& Zabihi, R. 2011. An application of a questionnaire of social and cultural capital to English language learning. English Language Teaching, 4: 151-157.

Powell, J. J. W., \& Solga, H. 2010. Analyzing the nexus of higher education and vocational training in Europe: A comparative-institutional framework. Studies in Higher Education, 35: 705-721.

Prieur, A., \& Savage, M. 2011. Updating cultural capital theory: A discussion based on studies in Denmark and in Britain. Poetics, 39: 566-580.

Rafee, N., Mustafa, Z., Shahabudin, F. A., Razali, A. M., \& Hassan, N. 2012. Level of English proficiency among science students of UKM. Procedia Social and Behavioral Sciences, 59: 663-669.

Rivera, L. A. 2011. Ivies, extracurriculars, and exclusion: Elite employers' use of educational credentials. Research in Social Stratification and Mobility, 29: 71-90.

Scholz, U., Doña, B. G., Sud, S., \& Schwarzer, R. 2002. Is general self-efficacy a universal construct? Psychometric findings from 25 countries. European Journal of Psychological Assessment, 18: 242-251.

Schultz, P. W., Nolan, J. M., Cialdini, R. B., Goldstein, N. J., \& Griskevicius, V. 2007. The constructive, destructive, and reconstructive power of social norms. Psychological Science, 18: $429-434$.

Schumann, J. 1978. Social and psychological factors in second language acquisition. In J. C. Richards (Ed.), Understanding second and foreign language learning: Issues and approaches: 163-178. Newbury: Rowley House.

Schwarzer, R., \& Jerusalem, M. 1995. Generalized Self-Efficacy scale. In J. Weinman, S. Wright \& M. Johnson (Eds.), Measures in health psychology: $A$ user's portfolio, causal and control beliefs: 35-37. Windsor, England: NFER-Nelson.

Scott, J. 2003. Social network analysis: $A$ handbook. London: Sage.

Servais, P., \& Jensen, J. M. 2001. The internationalization of industrial purchasing: The example of small Danish manufacturers. In C. N. Axinn \& P. Matthyssens (Eds.), Reassessing the internationalization of the firm (Advances in international marketing, volume 11): 227-254. Bradford, UK: Emerald.

Seth, M. J. 2002. Education fever: Society, politics, and the pursuit of schooling in South Korea. Honolulu: University of Hawaii Press.

Sørensen, E. S. 2005. Our corporate language is English: An exploratory survey of 70 DK-sited corporations' use of English. Master's Thesis, Aarhus School of Business, Aarhus, Denmark.

Spender, J.-C. 2005. Speaking about management education: Some history of the search for academic legitimacy and the ownership and control of management knowledge. Management Decision, 43: 1282-1292. 
Stone, M. 1974. Cross validity choice and assessment of statistical predictions. Journal of the Royal Statistical Society. Series B: Statistical Methodology, 36: 111-133.

Sturdy, A., \& Gabriel, Y. 2000. Missionaries, mercenaries or car salesmen? MBA teaching in Malaysia. Journal of Management Studies, 37: 979-1002.

Sullivan, L. E. 2009a. Extrinsic motivation. In L. E. Sullivan (Ed.), The Sage glossary of the social and behavioral sciences: 196. Thousand Oaks, CA: Sage.

Sullivan, L. E. 2009b. Intrinsic motivation. In L. E. Sullivan (Ed.), The Sage glossary of the social and behavioral sciences: 272. Thousand Oaks, CA: Sage.

Swartz, D. 1997. Culture and power. The sociology of Pierre Bourdieu. Chicago and London: University of Chicago Press.

Tange, H. 2008. Global commitment or local grievances? An assessment of the Grundfos language policy. Hermes, 41: 155-173.

Tange, H., \& Lauring, J. 2009. Language management and social interaction within the multilingual workplace. Journal of Communication Management, 13: 218-232.

Tsai, J. L., Ying, Y. W., \& Lee, P. A. 2001. Cultural predictors of self-esteem: A study of Chinese American female and male young adults. Cultural Diversity and Ethnic Minority Psychology, 7: 284-297.

Tung, P., Lam, R., \& Tsang, W. K. 1997. English as a medium of instruction in post-1997 Hong Kong: What students, teachers, and parents think. Journal of Pragmatics, 28: 441-459.

UNDP (United Nations Development Programme). 2011. Human Development Report 2011. Sustainability and Equity: A. Better Future for All. New York: United Nations Development Programme.

Useem, M., \& Karabel, J. 1986. Pathways to top corporate management. American Sociological Review: 184-200.

Vaara, E., \& Faÿ, E. 2011. How can a Bourdieusian perspective aid analysis of MBA education? Academy of Management Learning and Education, 10: 27-39.

Vaara, E., \& Faÿ, E. 2012. Reproduction and change on the global scale: A Bourdieusian perspective on management education. Journal of Management Studies, 49: 1023-1051.

Vaara, E., Tienari, J., Piekkari, R., \& Säntti, R. 2005. Language and the circuits of power in a merging multinational corporation. Journal of Management Studies, 42: 595-623.

Vallerand, R. J., Pelletier, L. G., Blais, M. R., Briere, N. M., Senecal, C., \& Vallieres, E. F. 1992. The academic motivation scale: A measure of intrinsic, extrinsic, and amotivation in education. Educational Psychological Measurement, 52: 1003-1017.

Wöchter, B., \& Maiworm, F. 2008. English-taught programmes in European higher education. The picture in 2007. Bonn: Lemmens.

Weißenberger, B. E., \& Angelkort, H. 2011. Integration of financial and management accounting systems: The mediating influence of a consistent financial language on controllership effectiveness. Management Accounting Research, 22: 160-180.

Westphal, J. D., \& Khanna, P. 2003. Keeping directors in line: Social distancing as a control mechanism in the corporate elite. Administrative Science Quarterly, 48: 361-398.

Wilson, K., Wolfe, B., \& Haveman, R. 2005. The role of expectations in adolescent schooling choices: Do youths respond to economic incentives? Economic Inquiry, 43: 467-492.

Wold, H. 1985. Systems analysis by partial least squares In P. Nijkamp, L. Leitner, \& N. Wrigley (Eds.), Measuring the unmeasureable. Marinus Nijhoff: Dordrecht.

Yang, A., \& Lau, L. 2003. Student attitudes to the learning of English at secondary and tertiary levels. System, 31: 107123.

Yeung, A. S., Lau, S., \& Nie, Y. 2011. Primary and secondary students' motivation in learning English: Grade and gender differences. Contemporary Educational Psychology, 36: $246-256$.

Zald, M. N. 2002. Spinning disciplines: Critical management studies in the context of the transformation of management education. Organization, 9: 365-385.

Zheng, P. 2004. Antecedents to international student inflows to UK higher education: A comparative analysis. Journal of Business Research, 67(2): 136-143.

Klarissa Lueg is assistant professor at Aarhus University School of Business and Social Sciences. She holds a PhD in sociology from the University of Technology Darmstadt. Her current research centers on internationalization and sociocultural diversity in higher education. Her work appeared in Studies in Higher Education, Journal of Social Science Education, Language and Communication at Work, and Race, Gender, and Class.

Rainer Lueg is associate professor at Aarhus University School of Business and Social Sciences. He holds a PhD in Business from WHU-Otto Beisheim School of Management. His current research focuses on strategic performance management systems, business models, and management learning. His work appeared in Management Accounting Research, Studies in Higher Education, Business Strategy and the Environment, European Management Journal, Advances in Accounting, and Journal of Accounting and Organizational Change. 
Copyright of Academy of Management Learning \& Education is the property of Academy of Management and its content may not be copied or emailed to multiple sites or posted to a

listserv without the copyright holder's express written permission. However, users may print, download, or email articles for individual use. 